\title{
Calibrating Macroprudential Policy to Forecasts of Financial Stability
}

\author{
Scott A. Brave \\ Federal Reserve Bank of Chicago \\ Jose A. Lopez \\ Federal Reserve Bank of San Francisco
}

August 2018

Working Paper 2017-17

http://www.frbsf.org/economic-research/publications/working-papers/2017/17

\section{Suggested citation:}

Brave, Scott A., Jose A. Lopez. 2018. "Calibrating Macroprudential Policy to Forecasts of Financial Stability,” Federal Reserve Bank of San Francisco Working Paper 2017-17.

https://doi.org/10.24148/wp2017-17

The views in this paper are solely the responsibility of the authors and should not be interpreted as reflecting the views of the Federal Reserve Bank of San Francisco or the Board of Governors of the Federal Reserve System. 


\title{
Calibrating Macroprudential Policy to Forecasts of Financial Stability
}

\author{
Scott A. Brave \\ Federal Reserve Bank of Chicago \\ Jose A. Lopez \\ Federal Reserve Bank of San Francisco
}

\begin{abstract}
The introduction of macroprudential responsibilities at central banks and financial regulatory agencies has created a need for new measures of financial stability. While many have been proposed, they usually require further transformation for use by policymakers. We propose a transformation based on transition probabilities between states of high and low financial stability. Forecasts of these state probabilities can then be used within a decisiontheoretic framework to address the implementation of a countercyclical capital buffer, a common macroprudential policy. Our policy simulations suggest that given the low probability of a period of financial instability at year-end 2017, U.S. policymakers need not have engaged this capital buffer.
\end{abstract}

Keywords: financial stability, countercyclical capital buffer, decision theory JEL Classification: G17, G18, G28

\footnotetext{
The views expressed herein are those of the authors and do not necessarily represent those of the Federal Reserve Banks of Chicago and San Francisco or the Board of Governors of the Federal Reserve System. We thank Òscar Jordà, Urmee Khan, Hashem Pesaran, Jan-Peter Siedlarek, and Loriana Pelizzon as well as participants at the 2018 IJCB Annual Research Conference, 2018 Canadian Economic Association Conference, 2017 Vienna-Copenhagen Conference on Financial Econometrics, 2017 SoFiE conference, 2017 IBEFA Summer conference, 2017 EBA Research Workshop, 2016 Federal Reserve Supervisory Surveillance conference, and the University of California, Riverside for their comments and suggestions. We thank Ben Cohen and Kevin Roberts for their exemplary research assistance.

Correspondence: sbrave@frbchi.org and jose.a.lopez@sf.frb.org Draft date: July 13, 2018.
} 


\section{Introduction}

The global financial crisis of 2007-2009 exposed an unprecedented level of systemic risk in national financial systems. The speed at which these risks developed and spread during the crisis often necessitated that central banks and financial regulatory agencies take large and immediate actions with the tools they had readily available. Subsequently, various national governments and international agencies, such as the Bank Committee on Banking Supervision (BCBS), have proposed and enacted a wide variety of new policy tools to address systemic risks and support financial stability going forward. Such policies have come to be known as macroprudential policies. ${ }^{1}$

Policymakers face substantial challenges in implementing macroprudential policies, beginning with the identification of the current state of financial stability and extending to the implementation of the chosen policy in a timely manner. The establishment of effective monitoring systems for financial stability is, therefore, a key element of macroprudential policymaking. Drehmann \& Juselius (2013) highlight the various challenges in selecting indicators of financial stability, such as the need for timely and stable policy signals; see also Brave \& Butters (2012b). In addition, new policy tools must be designed and implemented to address these financial stability concerns, such as the countercyclical capital buffer (CCyB) developed in Basel Committee on Banking Supervision (2010b). An example of how this tool is being employed for macroprudential policy purposes can be seen in the deliberations of the U.K.'s Financial Policy Committee, which activated its CCyB policy in March 2016, subsequently deactivated it in July 2016 after the Brexit vote, and re-activated it in June 2017:2

In this paper, we focus on the application of macroprudential policy in the spirit of current and proposed CCyB policies. Along with the U.K., several European countries have implemented CCyB policies, and the U.S. had implemented their policy as well as of October 14, 2016. $]^{3}$ These policies typically require monitoring financial conditions and deciding if such increased capital requirements should be implemented within a specified timeframe. Similarly, once the CCyB capital charges are in place, policymakers are then tasked with determining when changes in financial conditions warrant their removal; see

\footnotetext{
${ }^{1}$ Financial stability is defined by the European Central Bank (2013) as "a condition in which financial system intermediaries, markets, and market infrastructure can withstand shocks without major disruption in financial intermediation and, in general, supply of financial services." See Adrian et al. (2016) for an overview of macroprudential policies and available policy instruments, such as the countercyclical capital buffer examined in this paper.

${ }^{2}$ See Financial Policy Committee (2016) and Financial Policy Committee (2017).

${ }^{3}$ The U.S. policy was announced formally on September 8, 2016. For a full description of the policy, see Title 12 of the Code of Federal Regulations, Part 217, Appendix A. The BCBS maintains a database of national CCyB policies and policy actions at https://www.bis.org/bcbs/ccyb/
} 
Kowalik (2011) for further discussion. We focus here on the current U.S. policy and examine conditions that could suggest the triggering of the $\mathrm{CCyB}$ policy. Underlying our efforts are econometric models that capture the probability of transitioning between states of high or low financial stability, as measured using financial stability indicators (FSIs).

Researchers have proposed several FSIs in recent years to assist policymakers in determining the current state of national financial stability $\rfloor^{4}$ However, there is limited insight and experience on how to translate these indicators into policy actions; that is, policymakers are often provided with little or no guidance into how FSIs can be used in light of the decisions they must make. In this paper, we propose a transformation of FSIs that can more readily be mapped to the objective functions and decision processes of macroprudential policymakers. Namely, we propose that such indicators be collapsed into model-based probabilities of being in a state characterized by either high or low financial stability. While this transformation discards potentially useful information observed in the time-series dynamics of the FSI in question, it also hopefully provides a clearer signal for the policymakers' decisions. $5^{5}$ Notably, Brave \& Genay (2011) found in their analysis of Federal Reserve policy interventions during the financial crisis that persistent deviations of FSIs from their long-run averages - and not the potentially transient changes in these series - were what mattered for explaining the timing of Federal Reserve policy actions.

We examine a small set of FSIs currently in popular use with respect to monitoring systemic risk and macroprudential policy implementation. Our primary variable of interest is the ratio of private, nonfinancial credit to GDP (or the credit-to-GDP ratio) as proposed by the BCBS for use in national CCyB policies ${ }^{6}$ This variable has been shown to have a reasonably strong relationship with financial imbalances as per various studies. We examine this variable directly within a standard two-state Markov regimeswitching model as per Hamilton (1989). We incorporate FSIs into our analysis using the time-varying switching probability model proposed by Diebold et al. (1994), which uses these series as probability switching drivers. The FSIs we use in our specifications are predominantly credit market measures, such as the corporate bond spreads described

\footnotetext{
${ }^{4}$ See Bisias et al. (2012) for an overview of financial stability indicators as well as Brave \& Butters (2012a), Hartmann et al. (2013), and Aikman et al. (2015).

${ }^{5}$ See Brave \& Butters (2012b) and Drehmann \& Juselius (2013) for related analysis as well as Berge \& Jorda (2011) for discussion of a similar approach with respect to macroeconomic indicators related to the business cycle.

6 Basel Committee on Banking Supervision (2010b) provides the background information on the Baselproposed CCyB policy. Note that the Federal Reserve includes the credit-to-GDP ratio among many variables that might be used to inform CCyB decisions. Similarly, the United Kingdom's Financial Policy Committee is required by legislation to consider the credit-to-GDP ratio when setting its CCyB policy, but the committee has stated that "there was not a simple, mechanistic link between the buffer guide and the CCyB rate.” (U.K. Financial Policy Committee (March 23, 2016)).
} 
in Lopez-Salido et al. (2015) and Gilchrist \& Zakrajsek (2012), and financial condition indexes (FCIs) as proposed by Brave \& Butters (2012b).

The actual objects of interest for our analysis, however, are probability forecasts of transitioning into the state with a low degree of financial stability over the forthcoming eight quarters. The variation across models in these probabilities highlights the differing perspectives available to policymakers from alternative monitoring techniques. To formally account for this model uncertainty, we rank and combine the signals provided by each FSI specification using empirical Bayesian model averaging techniques, as described in Clyde \& George (2004).

Our emphasis on probability forecasts of the arrival of an adverse event is premised on the insights provided by Khan \& Stinchcombe (2015). In their work, they propose an analytical decision framework that combines hazard function analysis of the arrival of an adverse event, such as a hurricane, with a user's objective function about whether and when to enact a costly policy, such as an evacuation. In fact, they explicitly cite the example of a policymaker looking to maximize their objective function in light of a politically costly reform of a banking system, which clearly encompasses macroprudential policies in general and $\mathrm{CCyB}$ policies in particular. The authors characterize general firstand second-order conditions for determining when it may be appropriate to implement a policy or to delay action. Based on this general framework, we calibrate the policymaker's objective function for implementing the CCyB using a range of reasonable parameter values drawn from the literature and our estimated models. Our calibrated range of policy actions and implementation dates provide an overview of the policy actions available and the degrees of uncertainty that macroprudential policymakers face in their efforts.7 7

Specifically, we conduct a pseudo out-of-sample counterfactual analysis around the U.S. implementation of its proposed CCyB policy, which is scheduled to be fully phased in by 2019 . We examine the financial stability projections that policymakers would have faced in 2005.Q4, 2009.Q4, 2013.Q4, and 2017.Q4. Defining an adverse macroprudential event as four consecutive quarters of the model-implied low financial stability state, we use GDP growth projections from our models under baseline (i.e., no policy action) and implementation scenarios to calibrate the Kahn-Stinchcombe (KS) optimal action dates.

Our counterfactual cases illustrate the ability of the proposed framework to incorporate both current projections of financial stability and the relative costs of policy implementation into the macroprudential policymaker's loss function. While the choice of

\footnotetext{
${ }^{7}$ Please note that we do not take into account statements of policy precommitment and their potential effect and effectiveness. For example, the U.K. Financial Policy Committee announced in July 2016 that "it expected to maintain a $0 \%$ U.K. countercyclical capital buffer rate until at least June 2017," which they did.
} 
these projection dates is not definitive, they serve to highlight the effect of initial conditions on the optimal policy prescriptions. For example, for 2005.Q4, the model-implied starting point is projected to have a moderately high probability of entering the adverse macroprudential state. In contrast, for 2009.Q4, 2013.Q4, and 2017.Q4, the transition to the state of low financial stability is very unlikely. Accordingly, the weighted average hazard function as of 2005.Q4 was above the calibrated KS policy threshold for almost all eight quarters of the projection horizon, suggesting that the CCyB policy should have been implemented were it available to policymakers. In contrast, the model-weighted average hazard functions as of 2009.Q4, 2013.Q4, and 2017.Q4 were below the KS policy thresholds for almost all projection quarters, suggesting that policymakers could wait to act until perhaps a clearer signal of financial instability were to arrive.

The remainder of the paper is structured as follows. Section II provides an overview of the relevant literature on macroprudential policies and financial stability indicators. Section III presents our proposed transformations of the selected FSI into transition probabilities and hazard functions over the defined eight-quarter event horizon. Section IV presents the KS calibrations of simple policy objective functions as of our projection dates, and Section $\mathrm{V}$ concludes.

\section{Literature review}

Central banks and national governments have been given, and have taken on, financial stability responsibilities that are to be implemented using macroprudential policies. However, these new responsibilities have not been fully defined; for example, should policymakers only be concerned with guarding against financial instability among the market sectors and institutions that it is responsible for, such as the 2009 supervisory stress testing by the Federal Reserve, the commercial paper guarantees provided by the FDIC, and the TARP injections provided by the Treasury to bank holding companies? Or should they be concerned with broader events in other financial sectors, as suggested by the designation of insurance companies as systemically important financial institutions (SIFIs) by the Financial Stability Oversight Council (FSOC)? While many proposals and studies have been put forward and some legislative and regulatory steps have been taken, these policy questions remain challenging, even when direct responsibilities have been assigned.

One of the first steps toward addressing these questions, as proposed in the academic literature, was the development of financial stability indicators (FSIs) as early warning tools of developing financial crises. As noted by Danielsson et al.(2016), macroprudential policymakers are engaged in an active search for signals of future financial instability 
upon which to develop mitigating policy actions. An extensive literature around this topic related to international financial crises was initially developed in light of the international financial crises of the early 1990s; see Frankel \& Rose (1996), Kaminsky \& Reinhart (1999) as well as Reinhart \& Rogoff (2009) for a survey. More recent efforts, however, have focused on indicators of banking crises or credit overextension, which are more germane to the recent financial crisis; see Aikman et al. (2015) and Bisias et al. (2012) for recent surveys.

In general, a wide variety of FSIs have been shown to have useful properties as leading or "early-warning" indicators with regards to adverse developments in financial and macroeconomic variables. For example, Aramonte et al. (2013) found that several FSIs have short-term predictive ability with respect to stock returns and higher-frequency macroeconomic variables, such as industrial production, that are of interest to policymakers. An important distinction to make in the assessment of FSIs, however, is the difference between effectively summarizing financial conditions and forecasting macroeconomic conditions. For example, Aikman et al. (2015) found that their aggregate index Granger-causes the credit-to-GDP gap used for countercyclical capital buffer policies. In addition, Gadea Rivas \& Perez-Quiros (2015) note that credit and its transformations (e.g. gap or growth) has been shown in various recent studies to be empirically correlated with the probability of financial crises and the intensity of their effect on the broader economy. While studies have generally examined both questions to the extent that they are separable, the former is of greater relevance to macroprudential policymakers. We describe our selected FSIs in the next section.

In general, deriving optimal empirical models for forecasting requires detailed knowledge of the underlying decision problem ${ }^{8}$ Such knowledge is, however, not readily available in the context of macroprudential policies, as there is limited experience from which expected costs and benefits could be estimated. Nevertheless, it is still possible to begin incorporating the qualitative aspects of a policymakers' decision problem into the evaluation procedures for FSIs. As discussed in Drehmann \& Juselius (2013), several studies have used a loss function that accounts for a policymaker's preferences between Type I and Type II errors surrounding the identification of financial crises or other defined, adverse events. Such loss functions are mainly statistical in nature and are based on the receiver operating characteristic (ROC) curve. While this approach is reasonable within its own rights, it differs from the approach we propose.

Our specification of the policymaker's objective function is based on the work of

\footnotetext{
${ }^{8}$ See Granger \& Machina $(2006)$ as well as Pesaran \& Skouras (2002) for further discussion
} 
Khan \& Stinchcombe (2015), who put forth an analytical framework for examining decision problems of whether to act or delay action that explicitly incorporates a policymaker's objective function. Among their various examples, they cite "a politically painful reform of a banking system before the next financial crisis." A key element of this framework is a hazard function of the arrival of the adverse event of interest; i.e., the policymaker generates a probability vector forecast of the adverse event arriving over a specified time horizon. This probabilistic assessment is combined with the relative costs of enacting the specified policy and used to solve for the optimal policy implementation date. The functional form of the relative costs and benefits of the policy is quite flexible and accounts for time discounting and the relative effectiveness of the policy. We discuss the framework further with respect to our analysis in section 4. In particular, we adapt the framework for analyzing the implementation of countercyclical capital buffers.

\section{Transforming financial stability indicators into hazard functions}

Financial stability indicators (FSIs) need to be transformed in some way in order to provide sufficient context for use by policymakers in macroprudential policy decisions. For example, Brave \& Butters (2012b) collapse their preferred FSIs into event indicators, while Aikman et al. (2015) normalize their selected FSIs in order to graph them in various formats, such as radar and sunburst plots. In this section, we describe the FSIs that we examine in the context of CCyB policies for the U.S. and their transformation into the projected hazard functions required for the Khan \& Stinchcombe (2015) framework.

\subsection{Variables of interest}

Our main variable of interest is the ratio of U.S. private, nonfinancial credit to GDP (or the credit-to-GDP ratio), which has been proposed as the key monitoring variable for the implementation of national $\mathrm{CCyB}$ policies by the BCBS. Furthermore, the ratio has been shown to have good properties with respect to monitoring financial stability. Earlier work by Drehmann et al. (2011) as well as Drehmann \& Juselius (2013) helped establish this ratio as a potentially important policy variable. Subsequent work - such as by Jorda et al. (2011), Schularik \& Taylor (2012), Giese et al. (2014), Gadea Rivas \& Perez-Quiros (2015), and Aikman et al. (2016) - provides clear empirical support for the hypothesis that relatively high levels of this ratio make a macroeconomy less resilient to the arrival of adverse economic shocks.

The transformation proposed by the BCBS is to examine the gap between the ratio and its long-term trend, which is estimated using a one-sided Hodrick-Prescott filter with 
smoothing parameter $\lambda=400,000$. However, trend specifications using this filter have important shortcomings as described by Hamilton (2016b) and by Edge \& Meisenzahl (2011) with specific reference to CCyB policies? 9 We instead work with the components of the ratio and examine the growth rates of real private credit and GDP. Working with the ratio's components has been shown to produce more reliable leading indications of financial instability for the U.S., as per Brave \& Butters (2012a).

In addition, we examine several commonly-used FSIs that encompass different elements of the U.S. financial system. The first three FSIs reflect conditions in the U.S. corporate bond market and, thus, in the overall credit environment. The series are the spread between yields on seasoned long-term Baa-rated industrial bonds and comparable maturity Treasury securities, as discussed by Lopez-Salido et al. (2015), and the spread and excess bond premium measures developed by Gilchrist \& Zakrajsek (2012). The two spread variables are quite similar, while the excess bond premium is based on removing a modeled component capturing firm-specific default information from the spread. These three series have been shown to reflect current credit market sentiment and to be correlated with near-term economic growth, which are properties that meet standard criteria for use in setting macroprudential policy; see Drehmann \& Juselius (2013).

The remaining four FSIs that we examine stem primarily from the financial conditions indexes developed by Brave \& Butters (2012b) and made publicly available by the Federal Reserve Bank of Chicago. ${ }^{10}$ The National Financial Conditions Index (NFCI) and adjusted NFCI (ANFCI) are dynamic factors constructed from an unbalanced panel of 105 mixed-frequency indicators of financial activity, the latter of which is adjusted for prevailing economic conditions. ${ }^{11}$ The NFCI has been shown to be $95 \%$ accurate in identifying U.S. financial crises contemporaneously, with a decline to $62 \%$ accuracy at a lead of two years. In addition, Brave \& Butters (2012b) show that disaggregating the NFCI into subcomponents can enhance the nature of the signal provided regarding the degree of financial stability. In particular, we examine the NFCI Nonfinancial Leverage subindex, which signals financial imbalances with $50 \%$ accuracy contemporaneously and with $83 \%$ accuracy with a two-year lead. Correspondingly, we examine this FSI separately. Finally, we consider the year-over-year change in the Tier 1 leverage ratio for the U.S. banking system, which is defined as the aggregate sum of Tier 1 capital divided by the sum of

\footnotetext{
${ }^{9} \mathrm{~A}$ one-sided Hodrick-Prescott filter produces trend estimates that are very sensitive to the arrival of new data. Edge \& Meisenzahl (2011) show that the U.S. credit-to-GDP gap has been subject to sizable ex-post revisions that can be as as large as the gap itself; see Bassett et al. (2015) for further discussion.

${ }^{10}$ The data and background materials are available at https://www.chicagofed.org/publications/nfci/index

${ }^{11}$ Research suggests that financial conditions indexes that combine FSIs perform better in terms of state identification and measurement of macroeconomic effects than individual FSIs; see Hartmann et al. (2013).
} 
bank risk-weighted assets. This measure focusses on developments relative to financial stability arising within the banking system.

\subsection{Transition probabilities from Markov-switching models}

In their work on the effect of credit on the business cycle, Gadea Rivas \& PerezQuiros (2015) argue that "the key question for a policymaker is to what extent the level of credit-to-GDP (or its variations) observed in period $t$ increases or not the probability of being in a recession in $t+1$ or whether it changes the characteristics of future cyclical phases." While their results for a large panel of developed economies suggest that credit does not improve upon business cycle forecasts, our immediate concern regarding CCyB policies largely framed around the credit-to-GDP ratio requires that we re-examine this result. In this spirit, we use an alternative model specification that allows us to incorporate our set of chosen FSIs.

Our first step is to specify a univariate Markov-switching model, as per Hamilton (1989), capturing the joint dynamics of real GDP and credit growth in order to identify distinct states of high and low financial stability for the U.S. ${ }^{12}$ We denote these states as $\left\{S^{+}, S^{-}\right\}$, respectively. The motivation for our model can be seen in the decomposition of the growth rate of the credit-to-GDP ratio using log first differences, denoted by $\Delta l n$; that is,

$$
\Delta \ln \left(\frac{\text { Credit }}{\text { Nominal GDP }}\right)=\underbrace{\Delta \ln (\text { Credit })-\Delta \ln (\text { Price Level })}_{\text {Real Private Credit Growth }}-\underbrace{\Delta \ln (\text { Real GDP })}_{\text {Real GDP Growth }}
$$

Note that we deflate both GDP and private credit by the GDP deflator since Giese et al. (2014) found that real credit growth performs slightly better than nominal credit growth with respect to financial crisis notification. We model the transition between financial stability states based on changes in the underlying dynamics of real GDP growth, $\Delta \ln \left(G D P_{t}\right)$, and real credit growth, $\Delta \ln \left(C_{t}\right)$.

Our baseline model is

$$
\begin{aligned}
Y_{t} & =\alpha_{S}+\beta_{S} X_{t}+\epsilon_{t} \\
\epsilon_{t} & \sim N\left(0, \sigma^{2}\right),
\end{aligned}
$$

\footnotetext{
${ }^{12}$ In contrast, Hubrich \& Tetlow (2014) use a five-variable Markov-switching VAR (MS-VAR) model in their approach to assessing the effect of financial conditions on macroeconomic variables.
} 
where $Y_{t} \equiv \Delta \ln \left(G D P_{t}\right)$ and $\left.X_{t} \equiv\left\{\Delta \ln \left(G D P_{t-1}\right), \Delta \ln \left(C_{t}\right), \Delta \ln \left(C_{t-1}\right)\right)\right\}$ with the model's state-dependent parameters summarized in $\Theta_{S} \equiv\left\{\alpha_{S}, \beta_{S}\right\}{ }^{13}$ Our specification differs slightly from Gadea Rivas \& Perez-Quiros (2015) in that we do not restrict the effects of real credit growth in either state. As such, our specification allows for potentially richer joint dynamics within the two financial stability states.

To identify the low from the high financial stability state, we associate $\alpha_{S^{-}}<0$ with the former, such that real GDP growth is negative on average in this state. The states are then also assumed to follow a first-order Markov process with a constant transition probability matrix $\Omega$ with elements $p_{i j}$ denoting the transition probability from state $i$ to state $j$. The elements of this matrix are given by

$$
p_{i j}=\operatorname{Pr}\left(S_{t}=j \mid S_{t-1}=i, X_{t}, \Theta_{i}\right)=\Phi\left(\delta_{i}\right), \quad i, j \in S^{+}, S^{-},
$$

where $\Phi$ is the cumulative normal distribution.

To introduce the FSIs into our analysis, we instead use the time-varying transition probability model proposed by Diebold et al. (1994), which allows the transition probabilities of the first-order Markov process to depend on covariates $Z_{t}$. The transition probability matrix in this case is specified as

$$
\Omega_{t}=\left[\begin{array}{cc}
\Phi\left(\delta_{S^{+}}+\gamma Z_{t}\right) & 1-\Phi\left(\delta_{S^{+}}+\gamma Z_{t}\right) \\
1-\Phi\left(\delta_{S^{-}}+\gamma Z_{t}\right) & \Phi\left(\delta_{S^{-}}+\gamma Z_{t}\right)
\end{array}\right]
$$

where we introduce our selected FSIs into $Z_{t}$ on an individual basis in order to limit the number of estimated parameters. ${ }^{14}$ Given the small number of transitions in our data, we also find it useful to follow Amisano \& Fagan(2013) and require that the slope coefficients on $Z_{t}$ be common across the two states. ${ }^{15}$

Correspondingly, our approach creates eight model specifications. We combine

\footnotetext{
${ }^{13}$ In results not reported here, we could not reject the null hypothesis that $\sigma$ was equal across states, and, therefore, we restricted it to be state-invariant.

${ }^{14}$ Similarly, we limit their inclusion to only contemporaneous values. Note that Ajello et al. (2015) also use a contemporaneous credit growth variable in their specification of a crisis transition probability. In future work, we plan to explore in greater detail possible lead/lag relationships that could be exploited as well.

${ }^{15}$ Please note that the estimation was done in Matlab using the MSREGRESS package of Perlin (2015) extended to the time-varying transition probability case by Ding (2012). We use 36 random initializations of each model and pick the one that achieves the highest likelihood. For models with additional FSIs, we center our initializations around the converged parameter estimates of our baseline (constant transition probabilities) model. For instances where convergence is not achieved, we continue to draw random initializations until convergence.
} 
their results and projections using a Bayesian model averaging framework. ${ }^{16}$ To do so, we weight an object of interest for each model (e.g. state probabilities) by a measure of the model's fit of the data. Defining the set of model specifications as $\Xi$, the posterior probability $p\left(\Xi_{m} \mid Y, X, Z\right)$ assigned to each of our $m=8$ specifications is

$$
p\left(\Xi_{m} \mid Y, X, Z\right)=\frac{p\left(\Xi_{m}\right) \exp \left(-0.5 * B I C\left(\Xi_{m}\right)\right)}{\sum_{m} p\left(\Xi_{m}\right) \exp \left(-0.5 * B I C\left(\Xi_{m}\right)\right)}
$$

where $\operatorname{BIC}\left(\Xi_{m}\right)$ is the Bayesian information criterion and $p\left(\Xi_{m}\right)$ is a uniform prior over the model set.17

Figure 1 depicts one-sided (filtered) and two-sided (smoothed) estimates of the model-implied probability of the low financial stability state averaged across our eight model specifications for our entire sample period of 1985.Q1 to 2017.Q4. The shaded regions in the figure denote quarters where our model-weighted average (smoothed) probability of the low financial stability state exceeds $50 \%$. Three periods of low financial stability stand out in this figure: 1990.Q3 - 1991.Q1, 2000.Q3 - 2001.Q4, and 2006.Q2 - 2009.Q2. Each of these correspond with well-known periods of U.S. financial stress; i.e., the latter stages of the S\&L crisis and the credit crunch of the early '90s, the dot-com stock market bubble, and the recent global financial crisis. A fourth period of financial stress associated with the early stages of the S\&L crisis in the mid-1980s falls just below our $50 \%$ cutoff but is also apparent in the figure.

Figure 2 further summarizes the low and high states of financial stability identified by our models relative to real GDP and credit growth. For the sake of comparison, the figure also includes the credit-to-GDP gap. Generally speaking, the figure shows that periods of jointly accelerating or decelerating real credit and GDP growth tend to align with the low financial stability. Furthermore, although we use the growth rate of the credit-to-GDP ratio in our model, our methodology also captures well turning points in the credit-to-GDP gap commonly used to signal potential financial vulnerabilities. This can be seen by the ranges the three shaded regions in the figure (denoted with dashed lines) corresponding to NBER recessions. Our low stability state clearly leads several recessions ${ }^{18}$ In particular, we identify the occurrence of the low financial stability state

\footnotetext{
${ }^{16}$ Note that Lo Duca \& Peltonen (2013) also combine their candidate FSI variables within a multivariate discrete choice model.

${ }^{17}$ This Empirical Bayesian procedure and its benefits are described in greater detail in Clyde \& George (2004). One could substitute the BIC criterion for the likelihood of each model by simply eliminating the penalty that the BIC imposes on model complexity. In our case, this makes little difference as the number of estimated parameters is identical across models except for the baseline case.

${ }^{18}$ This is true whether or not we use two- or one-sided probability estimates from our models.
} 
two quarters prior to the 2001 recession and six quarters in advance of the 2008-2009 recession.

This leading signal can also be seen in several of the FSIs, shown in standard deviations from their unconditional means in figure 3 . Consistent with their purpose and previous research, the value of each of these seven financial stability indicators for macroprudential policy is evident in the figure, with large deviations from their historical means tending to align with our estimated periods of low financial stability as well as recessions. This is particularly true for the NFCI Nonfinancial Leverage subindex, which can be seen in the very large weight ( $84 \%$ ) given to it by our Bayesian model averaging procedure. Only one other FSI (the Leverage Ratio) receives a nontrivial weight ( $8 \%$ ) according to our procedure, suggesting that much of the timing of transitions between high and low states of financial stability can be captured exclusively by these two FSIs as well as the joint dynamics of real credit and GDP growth of our baseline model (8\%). To more closely examine the source of this property, we next take a closer look at our estimated parameters.

Table 1 presents the estimated coefficients for our eight model specifications. The top row of each panel reports the model weights assigned by our Bayesian model averaging procedure. The transition probability parameters for the models are then reported in the next set of panel rows. The $\delta_{1}$ estimates govern the probability of remaining in the high stability state, while the $\delta_{2}$ estimates govern the transition from the low stability to the high stability state. The impact of the FSIs on these probabilities for all but our baseline model is then summarized in our estimates of $\gamma$. Focusing on the baseline model, we find that the probability of remaining in the high stability state is roughly $97 \%$, while the probability of transitioning from the low stability back to the high stability state is about $16 \%$. The introduction of the FSIs tends to generate negative $\gamma$ estimates (except for the Leverage Ratio), most prominently for our best performing model using the NFCI Nonfinancial Leverage subindex. This negative coefficient suggests that as nonfinancial leverage increases over time, the probability of transitioning into the low stability state next period increases.

These parameters are then followed in the table by those governing the comovement of real GDP and real credit growth in our high $\left(S^{+}\right)$and low $\left(S^{-}\right)$financial stability states. Here, the estimated parameters vary importantly across the two states, but are similar across model specifications. The high stability state exhibits a positive and significant $\alpha_{1}$ constant, while the $\alpha_{2}$ constant for the low stability state is negative and significant. In contrast, the estimated coefficients on the lagged value of GDP growth are not statistically 
significant, though they are generally more negative in the low stability state, indicating a faster pace of mean reversion. Across the two states, the coefficients on both contemporaneous and lagged credit growth are generally significant, suggesting an effect of credit growth on real activity. For the high stability state, the lagged credit growth coefficient $\beta_{1}^{C_{t-1}}$ is positive and significant, while the contemporaneous coefficient is not. This result suggests that credit growth's contribution to GDP growth is milder and lagged during periods of financial stability. In contrast, in the low stability state, the $\beta_{2}^{C_{t}}$ coefficients are larger, positive, and significant contemporaneously while the lagged credit growth coefficients are not. It is predominately this property of the data (e.g. the contemporaneous positive comovement of real credit and GDP growth) that provides a leading indication of slipping into the state of low financial stability in our models. ${ }^{19}$

\subsection{Projecting state probabilities over the policy horizon}

The next step in transforming our selected FSIs into policy-relevant tools is to project the financial state probabilities out over the policy horizon of interest. Based on the notation presented in Hamilton (2016a), we discuss here the construction of the projected state probabilities needed for our policy exercise. Gadea Rivas \& Perez-Quiros (2015) note that the effects of credit growth on the business cycle are notable in-sample, but that there are no significant gains in forecasting business cycle turning points. However, given our particular need for such forecasts and the evidence presented above, we proceed under the assumption that the forecasted state probabilities should be a useful input to the policymaking process.

The relevant output from the Markov-switching models is the transition probabilities between financial stability states, summarized as

$$
\hat{\pi}_{T}=\left(\begin{array}{cc}
\hat{p}_{11} & \left(1-\hat{p}_{11}\right) \\
\left(1-\hat{p}_{22}\right) & \hat{p}_{22}
\end{array}\right)=\left(\begin{array}{ll}
\hat{p}_{11} & \hat{p}_{12} \\
\hat{p}_{21} & \hat{p}_{22}
\end{array}\right),
$$

where $\hat{p}_{i j}$ is the estimated transition probability from state $i$ at time $T$ to state $j$ at time $T+1$. To summarize the model-implied state, denote $\xi_{T}$ as a $(2 \times 1)$ vector that uses a value of one to indicate the true, but unobservable, state and a zero otherwise. For the estimated Markov models, we then generate

\footnotetext{
${ }^{19}$ To check the stability of our models, parameter estimates obtained by truncating our sample period initially to 2005.Q4 and adding back one year's worth of data at a time - namely, spanning 2005.Q4 through 2016.Q4 - can be found in similar tables 1A through 1L in the Appendix. While there is some variation across time periods that is evident in these tables, their overall impact on assessing the state of financial stability is small once our Bayesian model averaging procedure is employed, as discussed in the next section.
} 


$$
E\left[\hat{\xi}_{T} \mid S_{T-1}=i, \Omega_{T}\right]=\left(\begin{array}{c}
\operatorname{Pr}\left(S_{T}=1 \mid S_{T-1}=i\right) \\
\operatorname{Pr}\left(S_{T}=2 \mid S_{T-1}=i\right)
\end{array}\right)=\left(\begin{array}{c}
\hat{p}_{i 1} \\
\hat{p}_{i 2}
\end{array}\right),
$$

where the elements $\hat{p}_{i 1}+\hat{p}_{i 2}=1$. For forecasting purposes, define the matrix $\mathrm{P}$ whose $(j, i)$ element corresponds to $p_{i j}$, such that each column sums to 1 ; i.e.,

$$
P=\left(\begin{array}{ll}
p_{11} & p_{21} \\
p_{12} & p_{22}
\end{array}\right)
$$

The one-step-ahead forecast is then $E\left[\xi_{T+1} \mid \hat{\xi}_{T}\right]=P \hat{\xi}_{T}$, and the k-step-ahead forecast is $E\left[\xi_{T+k} \mid \hat{\xi}_{T}\right]=P^{k} \hat{\xi}_{T}$. We generate the forecasts for our weighted average hazard based on the individual model $\hat{\xi}_{T}$ estimates.

This framework allows us to generate the forecasted state probabilities over the number of quarters in the policymakers' decision horizon. The forecasted probabilities are then used to construct vector probability forecasts for a defined event of interest, which we denote as the conditional hazard function $H_{T}(k)$. For example, assume that the policymaker is concerned with entry into the financial instability state at any point over an eight-quarter forecast horizon 20 Using the notation above,

$$
H_{T}(k)=E\left[\operatorname{Pr}\left(S_{T+k}=2\right) \mid \hat{\xi}_{T}\right]=\left(P^{k} \hat{\xi}_{T}\right)_{(2,1)},
$$

which refers to the $(2,1)$ element in the product for each value of $k \in[1,8] . \mathrm{L}^{21}$

While straightforward to calculate, the usefulness of this event to a policymaker is likely limited. That is, a single quarter in the low financial stability state may not be sufficient to warrant a policy action, either because of uncertainty about the state itself or the overall effects of the policy occurring over more than one quarter. An alternative event of potential interest to policymakers is the probability of being in the adverse state for a consecutive number of quarters. ${ }^{22}$ For example, implementation of the CCyB may be phased

\footnotetext{
${ }^{20}$ The choice of an eight-quarter horizon for our work is based on other studies as well as the specifics of the countercyclical capital buffer policy. Drehmann \& Juselius (2013) argue that FSI signals should have appropriate timing to be useful for macroprudential policy responses. In particular, they suggest that the signal arrive at least 1.5 years before a financial crisis, but not more than five years before. Lo Duca \& Peltonen (2013) examine a projection horizon of six to eight quarters. Finally, Basel Committee on Banking Supervision (2010b) suggests that policymakers pre-announce an increase in the CCyB by four quarters.

${ }^{21}$ For the time-varying probability models, the out-of-sample projections should be conditioned on $Z_{t+k}$. At this point, we treat the variables as fixed at their end-of-sample values. In future work, we will examine the sensitivity of our results to this assumption.

${ }^{22}$ Edge \& Meisenzahl (2011) discuss different ways for policymakers to frame their event of interest or policy threshold for implementing the $\mathrm{CCyB}$, but none are based on defined financial stability projections as we propose. The authors discuss a policy threshold that is a high percentile, say $90 \%$, of the credit-to-GDP
} 
in over a one-year horizon such that policymakers would likely assess the probability of remaining in the adverse state in the four quarters after the policy's enactment. In this paper, we assume that policymakers are concerned with the probability of four consecutive quarters of financial instability, which we denote as $S^{-}$.

In particular, we frame the policymaker's problem as projecting out the hazard function at time $T$ of experiencing four consecutive quarters of the adverse $S^{-}$state over the eight-quarter horizon. Note that the policymaker will have in hand the model-implied state probabilities of the three quarters leading up to the projection point $T$ (i.e., quarters $T-2$ through $T$ ), which inform the probability of the four-quarter adverse event occurring in quarter $T+1$. With three conditional in-sample quarters and eight out-of-sample quarters to project over, we have $2,048\left(=2^{11}\right)$ state paths to consider. For each path, we determine the probability of the four-quarter adverse event occurring, and the likelihood of each path is then used to weight them into an overall hazard function for each of our eight Markov model specifications. We then average across the hazard functions of each model using our empirical Bayesian weights to obtain a single vector probability forecast $H_{T}(k)$.

The early warning indicator nature of our models should be useful for guiding macroprudential policy decisions. To test this, we consider a pseudo out-of-sample exercise where we estimate $H_{T}(k)$ by truncating our sample period initially to 2005.Q4 and then adding back one year's worth of data at a time - namely, spanning 2005.Q4 through 2017.Q4. The result of this exercise can be seen in figure 4. Each of the four panels of this figure contain hazard functions for four data samples over projection quarters (PQ) one through eight with the exception of the bottom, right panel which only contains the 2017.Q4 hazard values. The upper, left panel of the figure demonstrates quite clearly the effectiveness of our methodology in providing an early warning signal for the recent financial crisis. 23 Here, our hazard estimates begin in 2005.Q4 by signaling a maximum probability for the low financial stability state of $10 \%$ at PQ8 before jumping rapidly to $60 \%, 90 \%$, and 95\% in PQ1 for 2006.Q4, 2007.Q4, and 2008.Q4, respectively. ${ }^{24}$ After 2008.Q4, our hazard functions shift markedly lower, with each four-year period demonstrating progressively lower maximum values until 2017.Q4, where at PQ8 the probability of the low stability state remains below $2 \%$.

\footnotetext{
gap.

${ }^{23}$ Lo Duca \& Peltonen (2013) has a figure similar in spirit, but represents just their interest in the PQ6 result.

${ }^{24}$ It should be noted, however, that we are using revised data here. Given the large revisions that some of our data series experienced during this period, we are likely somewhat overstating the effectiveness of our methodology.
} 
In the next section, we provide additional context for these values in terms of judging in hindsight when and whether or not macroprudential policy actions would have been warranted. Before we do so, however, we take a closer look at the underlying models driving these results. Figure 5 plots the weight given to each of our eight model specifications for each year-end hazard function shown in figure 4 . The model rankings are largely consistent over the latter half of our sample period. Notably, from 2007.Q4 on the model including the NFCI Nonfinancial Leverage subindex receives the largest weight, which is in line with the findings of Brave \& Butters (2012b). The only other FSI that demonstrates an increase over the sample period in its weight is the Leverage Ratio, although its weight has also been declining since 2010.Q4. In contrast, the weight given to the baseline model, corporate bond spread measures (particularly the GZ spread and excess bond premium measures), and financial conditions indexes has fallen over time. The reason for this largely comes down to the ability of each FSI to provide a leading indication of the global financial crisis and recession.

Thus, in many respects, our most recent hazard estimates are very much defined by the characteristics of the last crisis, just as our hazard estimates for 2005.Q4 with their heavy reliance on corporate bond spread measures were for the early 2000s financial market disruptions. It is, therefore, reassuring for the early detection of future crises that despite these shortcomings our methodology still provides an early warning signal for the last crisis. That said, our methodology is also flexible enough that some additional uncertainty on this dimension could be incorporated. For example, we use a very agnostic prior in our model averaging procedure. A more informative prior could instead be used if there were indications that a particular model was no longer working as intended. We do not consider this possibility here, but simply raise it as a possibility that could enhance the discussion of macroprudential policy recommendations in the next section.

\section{Transforming hazard functions into policy recommendations}

Macroprudential policy is a relatively new responsibility for policymakers, and certainly one that is less familiar and examined than monetary policy. An important step in analyzing macroprudential policies is developing an objective function; that is, an explicit, even if simplified, statement of the relative costs and benefits of a policy action; see, for example, Peek \& Tootell (2015). Khan \& Stinchcombe (2015) (KS) provide just such an analytical framework, as we outline in this section. 


\subsection{KS first- and second-order conditions}

As KS state, "[a]t issue is the optimal timing of a costly ... precautionary measure: an evacuation before a hurricane landfall; or a politically painful reform of a banking system before the next financial crisis." It is the latter example that shapes our interpretation of their framework as a tool for examining macroprudential policies in general and policies regarding countercyclical capital buffers in particular. The KS framework can be applied at a decision point $\mathrm{T}$ when a policymaker must decide whether to enact a costly policy against the arrival of an adverse event, either immediately or in the near future after more information about the event arrival has been collected. The intuition is that the policymaker faces a hazard function of when the adverse event might arrive, as discussed above, and must decide whether to act.

The authors go on to note that "the optimal hesitation before implementing expensive precautionary measures involves waiting until the [estimated] hazard function is high enough and increasing..." Based on information up to time $\mathrm{T}$, define $t_{W}$ as the waiting time until the adverse event arrives, which has a continuous probability distribution function $f\left(t_{w}\right)$, a cumulative distribution function $F\left(t_{w}\right)$, and an associated hazard function $h\left(t_{w}\right)=f\left(t_{w}\right) /\left(1-F\left(t_{w}\right)\right)$. The optimal decision to be made at time $\mathrm{T}$ regarding when to act should balance the expected benefits of waiting (i.e., inaction) with the expected costs of the event arriving after the policy implementation.

Within the KS framework, define the present utility flow $\bar{u}>0$, which will be at risk at $T+t_{w}$ unless the mitigating policy is taken prior to that. If the measure is put in place prior to $t_{w}$ at a cost of $\mathrm{C}$, the utility flow declines to $\underline{u}>0$, such that $\bar{u}>\underline{u}>$ 0 . In the language of macroprudential policy, this definition reflects the policy intent of taking action to increase the resilience of the financial system or, equivalently, lowering economic loss when a crisis arrives. In addition, the policy is designed to lower the incidence of a financial crisis (i.e., the probability of the event actually occurring), which alters the probability of a crisis as follows:

$$
f_{\theta\left(t_{w} ; t_{1}\right)}=\left\{\begin{array}{cc}
f\left(t_{w}\right) & \text { if } t_{w}<t_{1} \\
(1-\theta) f\left(t_{w}\right) & \text { if } t_{w} \geq t_{1}
\end{array}\right\} ;
$$

that is, the probability of the event occurring declines after the policy is implemented at time $t_{1}$. The $\theta$ parameter is a measure of policy effectiveness and is bounded within the closed unit interval; i.e., a fully effective policy has $\theta=1$, while a completely ineffective policy has $\theta=0$.

Within the KS framework, the policymaker's optimal decision is to balance the cost 
of enacting the policy with the benefit of waiting as long as possible before doing so. The benefit of waiting is denoted $r C$, which is the annuitized value of the policy cost $\mathrm{C}$ at the discount rate $r$; i.e., the savings from not incurring $C$ at time T. The aggregate policy cost is the discounted value of the utility flow after enacting the policy minus its cost $\mathrm{C}$, all expressed in probabilistic terms based on the hazard function. In notational form, the cost is $([\theta \bar{u}+(1-\theta) \underline{u}] / r-C) * h\left(t_{w}\right){ }^{25}$ Thus, the first order condition for the optimal time to act, denoted as $t_{1}^{*}$, is

$$
h\left(t_{1}^{*}\right)=r C /([\theta \bar{u}+(1-\theta) \underline{u}] / r-C) .
$$

With respect to the second order condition, the intuition is that the policymaker wishes to defer incurring the cost of the action as long as waiting outweighs the potential loss in utility flow, which implies $h^{\prime}\left(t_{1}^{*}\right)>0$. In other words, the policymaker should act if the event probability is high enough and increasing before acting. Notably, these are characteristics of the hazard function presented in Figure 3. With respect to comparative statics, the optimal time is increasing in both $C$ and $r$ (i.e., the policymaker defers longer when the policy cost is higher) and decreasing in $\theta$ (i.e., more effective policies lead to higher benefits and thus earlier implementation).

\subsection{Calibration of the CCyB proposal}

Various studies, such as Cerra \& Saxena (2008), Furceri \& Mourougane (2012), and Romer \& Romer (2015), suggest that financial crises cause a significant and long-lasting reduction in GDP growth. It is such declines that the policymaker hopes to avoid or, at least, mitigate with the countercyclical capital buffer $(\mathrm{CCyB})$ policy, which requires an increase in regulatory capital for affected financial institutions once financial conditions have deteriorated sufficiently. In the U.S., the CCyB policy is the responsibility of the Federal Reserve and was first enacted in September 2016 with a CCyB rate of zero. ${ }^{26}$ In contrast, related policies were already in place and in use in Europe; for example, the Financial Policy Committee (FPC) of the Bank of England was established in June 2013. Translating the $\mathrm{CCyB}$ policy for the U.S. into the KS framework requires a formulation of the event hazard function, which was developed in the prior section, and the calibration of the various KS parameters described above.

The immediate cost of enacting the CCyB policy is incurred by the affected financial

\footnotetext{
${ }^{25}$ Note that $h\left(t_{w}\right)$ within the KS framework is an instantaneous hazard rate. In our work, we substitute our empirical hazard function as described in Section 3.3.

${ }^{26}$ See the Federal Reserve press release at http://www.federalreserve.gov/newsevents/pressreleases/bcreg20160908.htm
} 
institutions in raising the needed capital ${ }^{27}$ Thus, as a lower bound, we calibrate $C$ in terms of the firms' current capital base at time $T$; that is, we determine the dollar cost of the capital raise by the affected firms as required by the CCyB policy. The current size threshold for affected firms is $\$ 250$ billion in total assets with certain exceptions. These firms would be required to raise additional Tier 1 common equity (i.e., common stock) by a specified percentage of their total risk-weighted assets related to private credit up to a maximum value of 2.5 percent. The cost of this measure to the policymaker is zero since the firms actually incur the cost of raising this equity, but for the calibration exercise, we assume that the policymaker operates as if its cost is of equal magnitude; i.e., it internalizes the entire cost either by funding it directly or by assuming that the cost to the firms should be viewed as a social cost. Note that this calibration represents the lower bound of $C$ since the policymaker may consider other costs, such as the potential macroeconomic effect of raising bank capital requirements. ${ }^{28}$

Another important concern and potential cost for policymakers is the macroeconomic effect of raising bank capital requirements. For example, the FPC lowered its CCyB on banks' UK exposures from $0.5 \%$ to $0 \%$ in July 2016 based on the view that “[t]he availability of banks' capital resources, and their use to absorb shocks if risks materialize, insures against a tightening of bank credit conditions. 29 Such indirect costs are hard to measure and capture within the KS framework. The broader macroeconomic cost of raising regulatory capital requirements also seems to vary greatly across countries, time periods, and methodological approaches ${ }^{30}$ For these reasons, we capture the broader welfare costs of the $\mathrm{CCyB}$ within the $[\underline{u}, \bar{u}]$ utility flows of the KS framework, whose calibration we discuss in the next section.

The value of the rate $r$ should be both a function of the horizon over which the policy decision is being made and of the overall riskiness of the policy action ${ }^{31}$ The horizon over

\footnotetext{
${ }^{27}$ In the Federal Reserve's CCyB framework, the affected firms are banking organizations subject to the advanced approaches capital rules, which generally apply to those banking organizations with greater than $\$ 250$ billion in assets or more than $\$ 10$ billion in on-balance-sheet foreign exposures; see 12 CFR 217.11(b). As described in 12 CFR 217.100(b), the CCyB cost will differ across firms since it is weighted based on a firm's composition of private-sector credit exposures across national jurisdictions. However, we simplify this cost to be a common ratio across all firms for our study.

${ }^{28}$ See Basel Committee on Banking Supervision (2010a) and Firestone et al. (2017) for further discussion.

${ }^{29}$ BOE Financial Stability Report of 11/2016

${ }^{30}$ For the U.S., Edge \& Meisenzahl (2011) have examined the costs associated with CCyB policies, such as declines in lending volume and increased lending rates. Similarly, Berrospide \& Edge (2016) find in the post-crisis period that a one percentage point increase in equity capital increases one-year commercial loan growth between 10 to 15 percentage points. However, the effects are shown to vary across firms and over time. Carlson et al. (2013) find related results for a dataset of U.S. banks matched by geography and other business characteristics.

${ }^{31}$ See Bazelon \& Smetters (1999) for a discussion of the discount rates that should be applied for public policy projects.
} 
which monetary policy is said to be focused on is two years, and it is thus reasonable to assume that such a horizon would be the case for the CCyB policy, especially since it has a built-in, one-year activation delay. Regarding the riskiness of the action, we will assume, as above, that policymakers internalize the cost themselves and, thus, use the risk-free discount rate. The only parameter remaining then is $\theta$, the effectiveness of the chosen policy in lowering the probability of the adverse event occurring. Rather than estimate or calibrate this parameter, we instead examine a range of values to determine the overall sensitivity of our objective function $h\left(t_{1}^{*}\right)$ and obtain the implied range of $t_{1}^{*}$ solutions.

At this point, it is important to note that the projections and calibrations used in the subsequent analysis are conditional on the data available at time $T$ over the event horizon $T+\tau$. They are not structured to take account of the interactive adjustments in the economy subsequent to the policy actions regarding the CCyB. While this limitation is obvious, designing a response to the implementation of policies is beyond the scope of this work and beyond the scope of most policy decisions based on calibrations. Instead, our approach provides conditional projections using available data in a real-time setting that should provide key operational insights to policymakers.

\subsection{Calibration analysis}

External calibration. Our first calibration of the $[\underline{u}, \bar{u}]$ parameters is based on studies conducted by the Macroeconomic Assessment Group (MAG) established by the Financial Stability Board and the BCBS to examine the economic effect of the proposed Basel III capital requirements; see Macroeconomic Assessment Group (2010b) and Macroeconomic Assessment Group (2010a). In their analysis, the MAG implemented 97 different models to examine the effect of increased capital requirements on national GDP growth. They presented the range of model outcomes, and in our work, we use their $20^{\text {th }}$ and $80^{\text {th }}$ percentile values to establish a range of possible $\underline{u}$ values. For a one percentage point increase in bank capital, they found that real GDP growth declines by between -17 to -4 basis points at the one-year horizon for these two percentiles, respectively ${ }^{32} \mathrm{We}$ calibrate $\bar{u}$ with the corresponding baseline real GDP projection from the Survey of Professional Forecasters (SPF). We calibrate the $\underline{u}$ values as the two-year compounding of that year's SPF one-year forecast minus the two MAG percentiles noted. The values used for each year of our analysis are reported in Table 2.

Table 2 presents the external calibration values used for our KS analysis as of four separate year-end quarters: 2005.Q4, 2009.Q4, 2013.Q4, and 2017.Q4. The first quarter

\footnotetext{
${ }^{32}$ Firestone et al. (2017) suggest a decrease in real GDP growth within the range of $(-27,-8)$ basis points for a one percentage point increase in bank capital; see their Table 12.
} 
of analysis corresponds to the run-up to the financial crisis, while the latter three correspond to periods that are relatively more stable, although with slightly different probabilities of entering the low financial stability state. The calibration of $C$ is the required increase in bank capital, which is based on the total risk-weighted assets (RWA) for the affected firms ${ }^{33}$ As proposed, the $\mathrm{CCyB}$ policy applies only to banking organizations subject to the advanced capital rules, which generally are those with greater than $\$ 250$ billion in assets or more than $\$ 10$ billion in on-balance-sheet foreign exposures. For the twelve banking firms that met this threshold as of 2017.Q4, their total RWA was \$7.7 trillion dollars, which suggests a $0.25 \%$ CCyB need of $\$ 19.25$ billion. Note that this capital amount must be raised within one calendar year of policy enactment. We assume that the number of affected firms would be the same for 2005.Q4, 2009.Q4, and 2013.Q4. Thus, in 2005.Q4, we calibrate $C$ as $0.25 \%$ of $\$ 4.5$ trillion, which is $\$ 11.25$ billion. The corresponding amount then for both 2009.Q4 and 2013.Q4 is $\$ 17.0$ billion. As discussed, our calibration discount rate is the two-year risk-free Treasury rate, as reported in the table.

The bottom rows of Table 2 show the calibrated probability values from our estimated hazard function that optimize the KS first-order condition for values of $\theta$ across our three sample periods. These calibrated KS values are the recommended policy implementation thresholds based on the total capital to be raised by the affected banks under a $0.25 \%$ implementation of the CCyB policy. Over all four sample periods, the calibrated probability values range from $1.33 \%$ to $2.63 \%$, which is a relatively low threshold in each case. The policy intuition here is that the cost of the $\mathrm{CCyB}$ capital raise in this calibration is quite low relative to the overall potential benefit of avoiding a substantial decline in real GDP. Based on these threshold values, we can identify calibrated policy implementation dates that incorporate both the policymaker's objective function and current financial stability projections.

Table 3 summarizes the calibrated implementation quarters across our four projection points and eight model specifications as well as the Bayesian model-weighted average outcome shown in Figure 6. For the policymaker at 2005.Q4, the model-weighted average hazard function suggests that the $\mathrm{CCyB}$ policy should be enacted within the four-quarter implementation period after announcement; i.e., the threshold values depicted in the grey range at the very bottom of the graph are breached by the model-weighted average haz-

\footnotetext{
${ }^{33} \mathrm{We}$ used the variable BHCK A223 (total risk-weighted assets) from the consolidated Y-9C reporting forms. Note that the current proposal suggests that the CCyB rate be applied only to firms' private sector credit exposures, which is a subset of total RWA and thus a lower number than the one used here. In addition, the applicable $\mathrm{CCyB}$ amount for a banking organization is equal to the weighted average of $\mathrm{CCyB}$ amounts established by the Board of Governors for the national jurisdictions where the banking organization has private-sector credit exposures.
} 
ard value after PQ1. As shown in the first column of table 3, given the relatively low cost of the required capital raise, seven of the eight models suggest that the policymaker should consider implementing the policy within the coming year given the projected financial stability conditions. The policymaker at 2009.Q4, 2013.Q4 and 2017.Q4 faces a contrasting set of conditions with a near zero hazard function for the first three projection quarters. For the policymaker at 2009.Q4, a much lower initial level and slope of the model-weighted average hazard function than in 2005.Q4 keeps it below the threshold for action until PQ8. This is the case despite, as shown in the second column of table 3, six of the eight models suggesting implementation of the CCyB in PQ4-PQ6. A similar pattern is also observed for 2013.Q4 and 2017.Q4, as shown in the third and fourth columns of table 3, with the KS threshold values for several of the eight models suggesting implementation in PQ4-PQ7. For all three periods, the NFCI Nonfinancial Leverage subindex specification that dominates the Bayesian model averaging has a hazard function that is quite low, causing the model-weighted average hazard value not to exceed the KS thresholds until PQ8 or later. These outcomes illustrate how even a relatively low cost policy might not be reasonably implemented by policymakers when facing a benign projection for financial stability.

Internal calibration. Our second calibration of the $[\underline{u}, \bar{u}]$ parameters is based on our estimated model parameters, as previously discussed and which we term as an internal calibration. We define our model-based utility flows over the projection horizon as the long-term expectations of GDP growth conditional upon both the financial stability state and the expected credit growth variable. In notation, the model-implied growth rate in state $\mathrm{S}$ is

$$
\hat{\mu}_{S}=\frac{\hat{\beta}_{S, \text { constant }}+\left(\hat{\beta}_{S, \text { credit } 0}+\hat{\beta}_{S, \text { credit }-1}\right) * E[\text { credit }]}{\left(1-\hat{\beta}_{S, G D P-1}\right)},
$$

where the $\hat{\beta}_{S}$ terms correspond to the state-dependent estimated parameters in our model specification and E[credit] is the historical average of the credit growth variable in our data. Table 4 presents the calibration parameters and highlights that we set the utility flows as $\bar{u}=G D$ Plevel $* \mu_{+}$and $\underline{u}=$ GDPlevel $* \mu_{-}$.

The bottom rows of Table 4 show the calibrated hazard (or probability) values that optimize the KS first-order condition for various values of $\theta$ across our four sample periods. As before, these calibrated KS values are the recommended policy implementation thresholds based on the total capital to be raised by the affected banks under a $0.25 \%$ implementation of the CCyB policy. Over all four sample periods, the calibrated probability values range from $1.19 \%$ to $16.29 \%$, which is a relatively wide range due to the relatively 
large differences in state-contingent utility flows that arise from our parameter estimates. The policy intuition here is that the relative cost of the $\mathrm{CHB}$ capital raise is quite sensitive to its effectiveness (i.e., the calibrated value of $\theta$ ) since the spreads between growth rates across the two states are much larger. Table 5 summarizes the calibrated implementation quarters across our four projection points and eight model specifications as well as the Bayesian model-weighted average outcome shown in Figure 7

As before, for the policymaker at 2005.Q4, the model-weighted average hazard function suggests that the CCyB policy should be enacted within the four-quarter implementation period after announcement regardless of the perceived effectiveness of the policy; i.e., the threshold values depicted in the bottom of the grey range in figure 7 are breached by the model-weighted average hazard value in PQ1 and those at the top of the grey range are breached in PQ2. As shown in the first column of table 5, given the relatively low cost of the required capital raise, implementing the policy within the coming year would be warranted based on the projected financial stability conditions of six of the eight models. The decision to be made is more nuanced for the policymaker at 2009.Q4, where the threshold for action is not breached until PQ6, and even then only in the case where the policy is assumed to be highly effective (i.e. for a large value of $\theta$ ). The policymaker at 2013.Q4 and 2017.Q4 faces a contrasting set of conditions. As shown in the third and fourth columns of table 5, the KS lower threshold values for policy implementation for most models falls between PQ4 and PQ8. However, since the highest weight is placed on the specification using the NFCI Nonfinancial Leverage subindex whose threshold date is beyond PQ8, the weighted average hazard values do not meet the thresholds for action over the projection horizon for any value of $\theta$.

These results highlight the importance of defining the $[\underline{u}, \bar{u}]$ calibration parameters in the KS objective function. Both calibrations provide insight into the policymaker's decision process and highlight the need to carefully define these values. While our two chosen calibrations may be quite different, they highlight the potential value of the framework for policy discussion; i.e., the framework organizes the various components of the $\mathrm{CCyB}$ decision process into a format that enhances policy discussion.

Calibration of the CCyB rate. The policy recommendations discussed above are based on whether or not to enact the CCyB policy using the rate of $0.25 \%$ at the beginning of a projection quarter. An alternative policy analysis that can be conducted within this framework is to ask today what $\mathrm{CCyB}$ rate should be enacted in a particular projection quarter. In terms of the KS notation, instead of setting all of the calibration parameters to see at what date it would be reasonable to act, this alternative analysis fixes the policy enactment date and examines what the policy rate should be relative to the KS first order 
condition at each date.

Figures 8 and 9 present this alternative analysis for our four time periods and our internal and external calibration parameters. Please note that as the CCyB policy is to be implemented over the four quarters after its announcement, we present our implied CCyB rates only for PQ4 through PQ8. As of year-end 2005, the clear policy recommendation from both figures based on the high probability of tipping into the adverse state is that a $\mathrm{CCyB}$ rate in excess of $0.25 \%$ should be put in place, with the optimal rate rising from about $1 \%$ to roughly $2 \%$ across our two calibrations as action is delayed from PQ4 to PQ8 and depending on the MAG and $\theta$ values used in the calibration.

The other three sample periods provide more nuanced answers. The results for these periods show that if the policymaker wanted to enact a non-zero CCyB rate, it would be in effect in PQ4. However, given that the calibrated value is well below 25 basis points, it would be reasonable to recommend inaction. In fact, under this rule-of-thumb, the policymaker would not need to act at all over the projection horizon in 2013.Q4 and 2017.Q4. However, a policymaker at year-end 2009 may prefer to just barely act at PQ6PQ8 if the $\theta$ value was close to one in the internal calibration and at PQ7-PA8 in the external calibration. In both cases, the policymaker need not act immediately given the relatively low adverse event probabilities and, in fact, could even delay action for a few quarters in hoping for a clearer signal of potential financial instability.

\section{Conclusion}

The explicit introduction of macroprudential responsibilities and policies at central banks and financial regulatory agencies has created a need for new aggregate measures of national financial stability. While many have been proposed, these measures typically require further transformation or calibration for use by macroprudential policymakers; i.e., for introduction into decision-making processes and policy objective functions. We propose a transformation based on modeled transition probabilities between states of high and low financial stability using common financial stability indicators. Probability estimates from these Markov regime-switching models can then be used directly within a decision-theoretic framework, as per Khan \& Stinchcombe (2015), structured to address the implementation of countercyclical capital buffers.

Our calibrated examples using data as of 2005.Q4, 2009.Q4, 2013.Q4, and 2017.Q4 illustrate how this framework can be used to make macroprudential policy recommendations that incorporate both policymakers' objective functions and financial stability projections. For the 2005.Q4 projection date, we found that the moderate likelihood of deteri- 
orating financial stability according to our measures and the relatively low cost of raising CCyB capital amounts suggested that policymakers should have considered implementation of the countercylical capital buffer immediately if this macroprudential tool would have been available to them. For the other three projection dates, the opposite pattern holds, with the suggested CCyB implementation dates being up to at least six to eight quarters ahead.

Our calibration exercises demonstrate how our proposed analytical framework could be used constructively for macroprudential policymaking. By translating projected policy costs and benefits across reasonably estimated hazard functions of adverse events, this approach would provide policymakers with a concrete framework for assessing if and when to act. Clearly, a variety of research questions remain to be addressed regarding the policy of interest, the adverse event to be avoided, the specification of the projected hazard functions and their associated financial stability measures, and the policy costs and benefits. However, by providing a straightforward analytical framework for approaching this problem with a closed-form solution, we hope to contribute to the effective design, ongoing implementation, and assessment of macroprudential policies.

\section{References}

Adrian, T., de Fontnouvelle, P., Yang, E., \& Zlate, A. (2016). Macroprudential policy: Case study from a tabletop exercise. Federal Reserve Bank of New York Economic Policy Review, forthcoming.

Aikman, D., Kiley, M. T., Lee, S. J., Palumb, M. G., \& Warusawitharana, M. N. (2015). Mapping heat in the U.S. financial system. Finance and Economics Discussion Series 2015-059. Washington: Board of Governors of the Federal Reserve System.

Aikman, D., Lehnart, A., Liang, N., \& Modugno, M. (2016). Financial vulnerabilities, macroeconomic dynamics, and monetary policy. Finance and Economics Discussion Series 2016-055. Washington: Board of Governors of the Federal Reserve System.

Ajello, A., Laubach, T., Lopez-Salido, D., \& Nakata, T. (2015). Financial stability and optimal interest-rate policy. Finance and Economics Discussion Series 2016-067. Washington: Board of Governors of the Federal Reserve System.

Amisano, G., \& Fagan, G. (2013). Money growth and inflation: A regime switching approach. International Journal of Money and Finance, 33, 118-145.

Basel Committee on Banking Supervision. (2010a). An assessment of the long-term economic impact of stronger capital and liquidity requirements (Vol. August). 
Basel Committee on Banking Supervision. (2010b). Guidance for national authorities operating the countercyclical capital buffer (Vol. December).

Bassett, W., Daigle, A., Edge, R., \& Kara, G. (2015). Credit-to-GDP trends and gaps by lenderand credit-type. FEDS Notes. December 3.

Bazelon, C., \& Smetters, K. (1999). Discounting inside the Washington D.C. Beltway. Journal of Economic Perspective, 13, 213-228.

Berge, T. J., \& Jorda, O. (2011). Evaluating the classification of economic activity into recessions and expansions. American Economic Journal: Macroeconomics, 97(3), 246-277.

Berrospide, J. M., \& Edge, R. (2016). The impact of Basel III capital regulation on bank lending. Manuscript.

Bisias, D., Flood, M., Lo, A. W., \& Valavanis, S. (2012). A survey of systemic risk analytics. Office of Financial Research Working Paper \#1.

Brave, S. A., \& Butters, R. A. (2012a). Detecting early signs of financial instability. Chicago Fed Letter. Federal Reserve Bank of Chicago(303).

Brave, S. A., \& Butters, R. A. (2012b). Diagnosing the financial system: Financial conditions and financial stress. International Journal of Central Banking.

Brave, S. A., \& Genay, H. (2011). Federal Reserve policies and financial market conditions during the crisis. Chicago Fed Letter. Federal Reserve Bank of Chicago(4).

Carlson, M., Shan, H., \& Warusawitharana, M. (2013). Capital ratios and bank lending: A matched bank approach. Journal of Financial Intermediation, 22, 663-687.

Cerra, V., \& Saxena, S. (2008). Growth dynamics: The myth of economic recovery. American Economic Review, 98, 439-457.

Clyde, M., \& George, E. I. (2004). Model uncertainty. Statistical Science, 19(1), 81-94.

Danielsson, J., Valenzuela, M., \& Zer, I. (2016). Learning from history: Volatility and financial crises. Systemic Risk Center Discussion Paper(57).

Diebold, F. X., Lee, J.-H., \& Weinbach, G. C. (1994). Regime switching with time-varying transition probabilities. In Nonstationary time series analysis and cointegration (p. 283-302). Oxford: Oxford University Press.

Ding, Z. (2012). An implementation of Markov regime switching model with time varying transition probabilities in MATLAB. Manuscript. 
Drehmann, M., Borio, C., \& Tsatsaronis, K. (2011). Anchoring countercyclical capital buffers: The role of credit aggregates. International Journal of Central Banking, 7, 189-240.

Drehmann, M., \& Juselius, M. (2013). Evaluating early warning indicators of banking crises: Satisfying policy requirements. Bank for International Settlements Working Papers \#421.

Edge, R. M., \& Meisenzahl, R. R. (2011). The unreliability of Credit-to-GDP ratio gaps in realtime: Implications for countercyclical capital buffers. International Journal of Central Banking, 7(4), 261-298.

European Central Bank. (2013). Financial Stability Review, November.

Financial Policy Committee. (2016). Record of the financial policy committee meetings (Vol. July).

Financial Policy Committee. (2017). Record of the financial policy committee meetings (Vol. June).

Firestone, S., Lorenc, A., \& Ranish, B. (2017). An empirical economic assessment of the costs and benefits of bank capital in the u.s. Board of Governors of the Federal Reserve System, Finance and Economics Discussion Series(2017-034).

Frankel, J., \& Rose, A. (1996). Currency crashes in emerging markets: An empirical treatment. Journal of International Economics, 41, 351-366.

Furceri, D., \& Mourougane, A. (2012). The effect of financial crises on potential output: New empirical evidence from OECD countries. Journal of Macroeconomics, 34, 822-832.

Gadea Rivas, M. D., \& Perez-Quiros, G. (2015). The failure to predict the Great Recession - a view through the role of credit. Journal of European Economic Association, 13, 534-559.

Giese, J., Andersen, H., Bush, O., Castro, C., Farag, M., \& Kapadia, S. (2014). The Credit-toGDP gap and complementary indicators for macroprudential policy: Evidence from the u.k. International Journal of Finance and Economics, 19, 25-47.

Gilchrist, S., \& Zakrajsek, E. (2012, June). Credit spreads and business cycle fluctuations. American Economic Review, 50(2).

Granger, C. W., \& Machina, M. J. (2006). Forecasting and decision theory. In Handbook of economic forecasting, Volume I. Elsevier B.V.

Hamilton, J. D. (1989). A new approach to the economic analysis of nonstationary time series and the business cycle. Econometrica, 57, 357-384. 
Hamilton, J. D. (2016a). Macroeconomic regimes and regime shifts. NBER Working Paper \#21863.

Hamilton, J. D. (2016b). Why you should never use the Hodrick-Prescott filter. Manuscript, $U C S D$.

Hartmann, P., Hubrich, K., \& Kremer, M. (2013). Melting down: Systemic financial instability and the macroeconomy. Leiniz Information Centre for Economics.

Hubrich, K., \& Tetlow, R. J. (2014). Financial stress and economic dynamics: The transmission of crises. European Central Bank Working Paper Series \#1728.

Jorda, O., Schularick, M., \& Taylor, A. M. (2011). Financial crises, credit booms, and external imbalances: 140 years of lessons. IMF Economic Review, 59(2), 340-378.

Kaminsky, G., \& Reinhart, C. (1999). The twin crises: The causes of banking and balance of payments problems. American Economic Review, 89, 473-500.

Khan, U., \& Stinchcombe, M. B. (2015). The virtues of hesitation: Optimal timing in a nonstationary world. American Economic Review, 105, 1147-1176.

Kowalik, M. (2011). Countercyclical capital regulation: Should bank regulators use rules or discretion? Federal Reserve Bank of Kansas City Economic Review, 2, 59-80.

Lo Duca, M., \& Peltonen, T. A. (2013). Assessing systemic risks and predicting systemic events. Journal of Banking and Finance, 37, 2183-2195.

Lopez-Salido, D., Stein, J. C., \& Zakrajsek, E. (2015). Credit-market sentiment and the business cycle. Finance and Economics Discussion Series 2015-028. Washington: Board of Governors of the Federal Reserve System.

Macroeconomic Assessment Group. (2010a). Assessing the macroeconomic impact of the transition to stronger capital and liquidity requirements: Final report (Vol. December).

Macroeconomic Assessment Group. (2010b). Assessing the macroeconomic impact of the transition to stronger capital and liquidity requirements: Interim report (Vol. August).

Peek, E. S. R., Joe, \& Tootell, G. M. (2015). Should U.S. monetary policy have a ternary mandate? Federal Reserve Bank of Boston, Manuscript.

Perlin, M. (2015). MS_Regress: The MATLAB package for Markov regime switching models. Manuscript.

Pesaran, M. H., \& Skouras, S. (2002). Decision-based methods for forecast evaluation. In A companion to economic forecasting. Oxford, Basil Blackwell. 
Reinhart, C. M., \& Rogoff, K. S. (2009, May). The aftermath of financial crises. American Economic Review, 99(2), 466-472.

Romer, C. D., \& Romer, D. H. (2015, May). New evidence on the impact of financial crises in advanced countries. NBER Working Paper, 99(21021).

Schularik, M., \& Taylor, A. (2012, April). Credit booms gone bust: Monetary policy, leverage cycles, and financial crises, 1870-2008. American Economic Review, 102(2), 1029-1061. 
7 Figures and Tables 


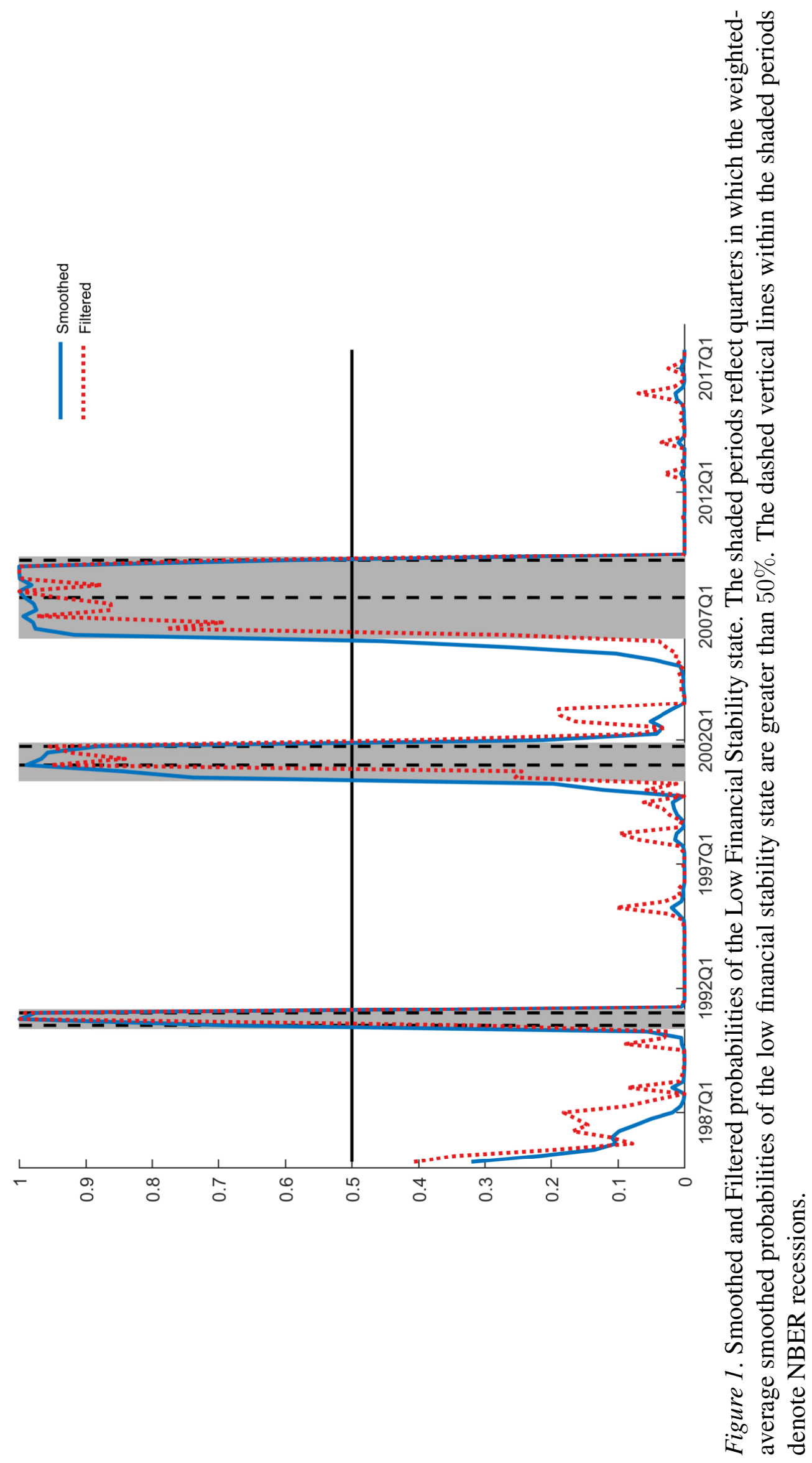




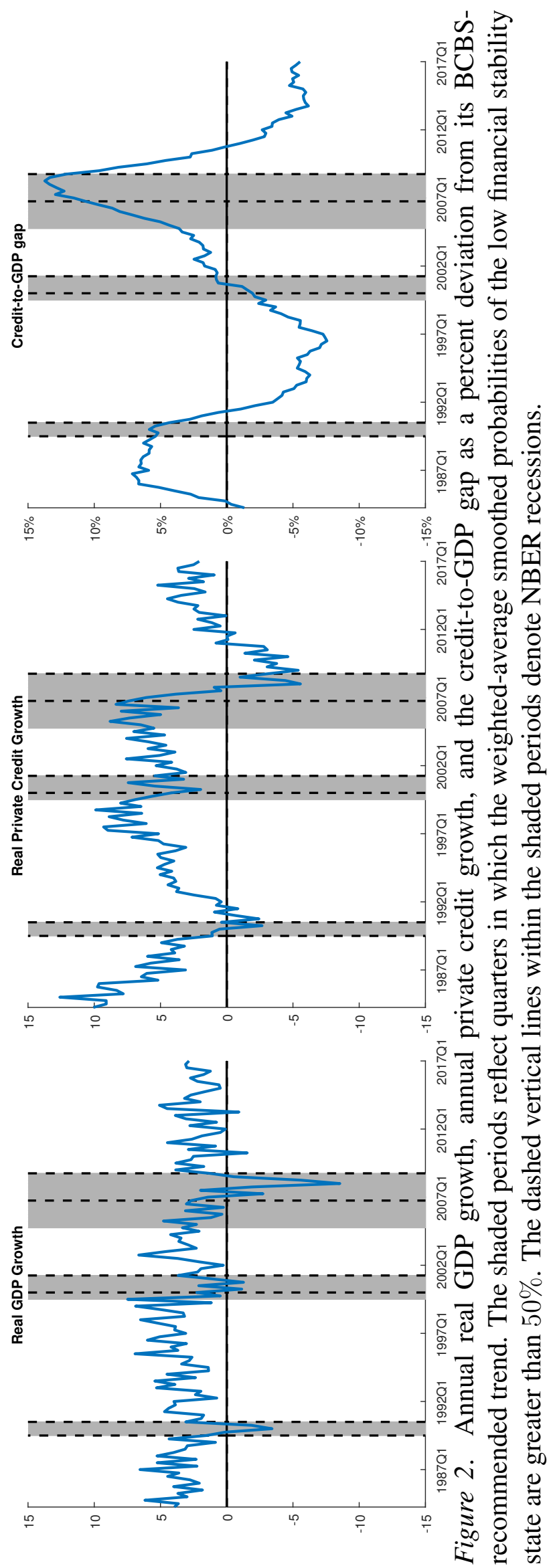



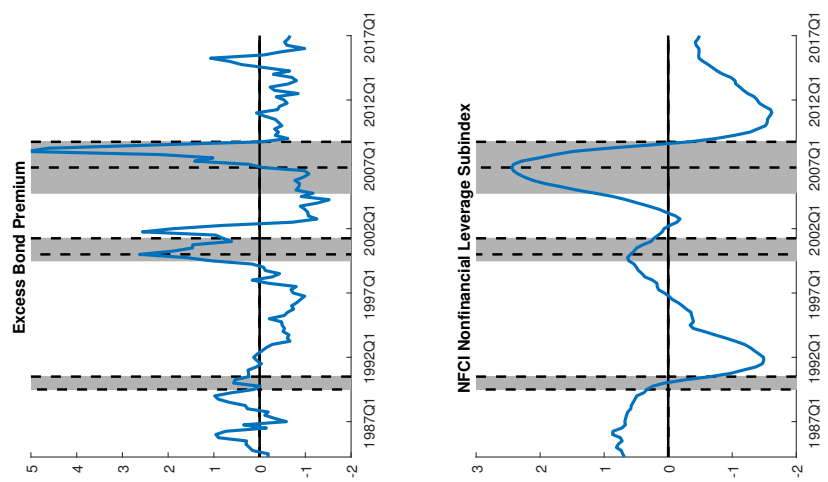

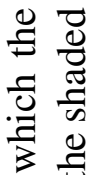

ఫั

勿

营.

氖

各

巳

जิ

\& 20

寄
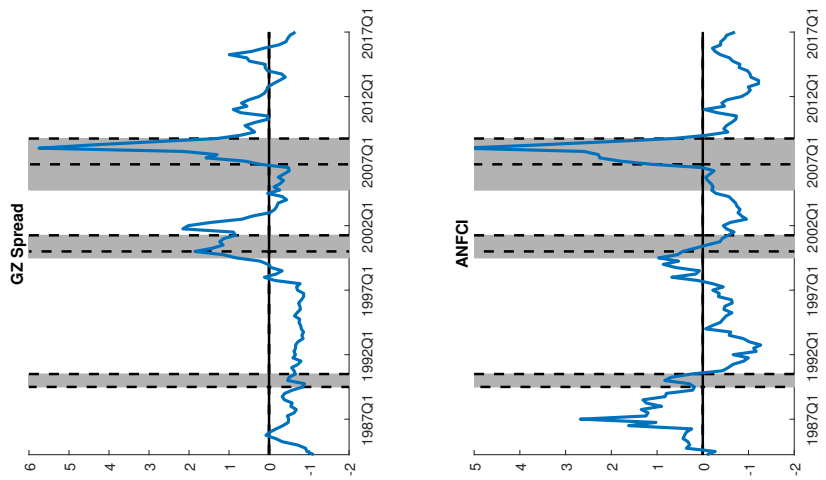

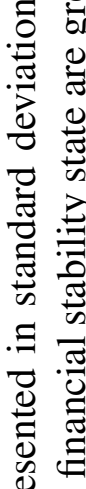
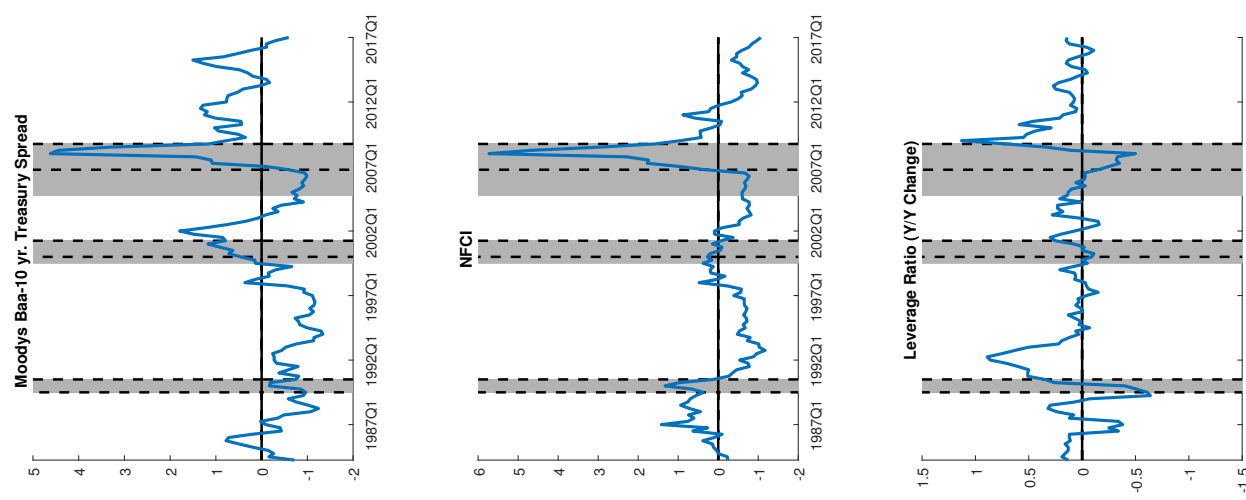

党

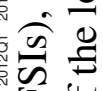

It

वै :ै

?

氞 

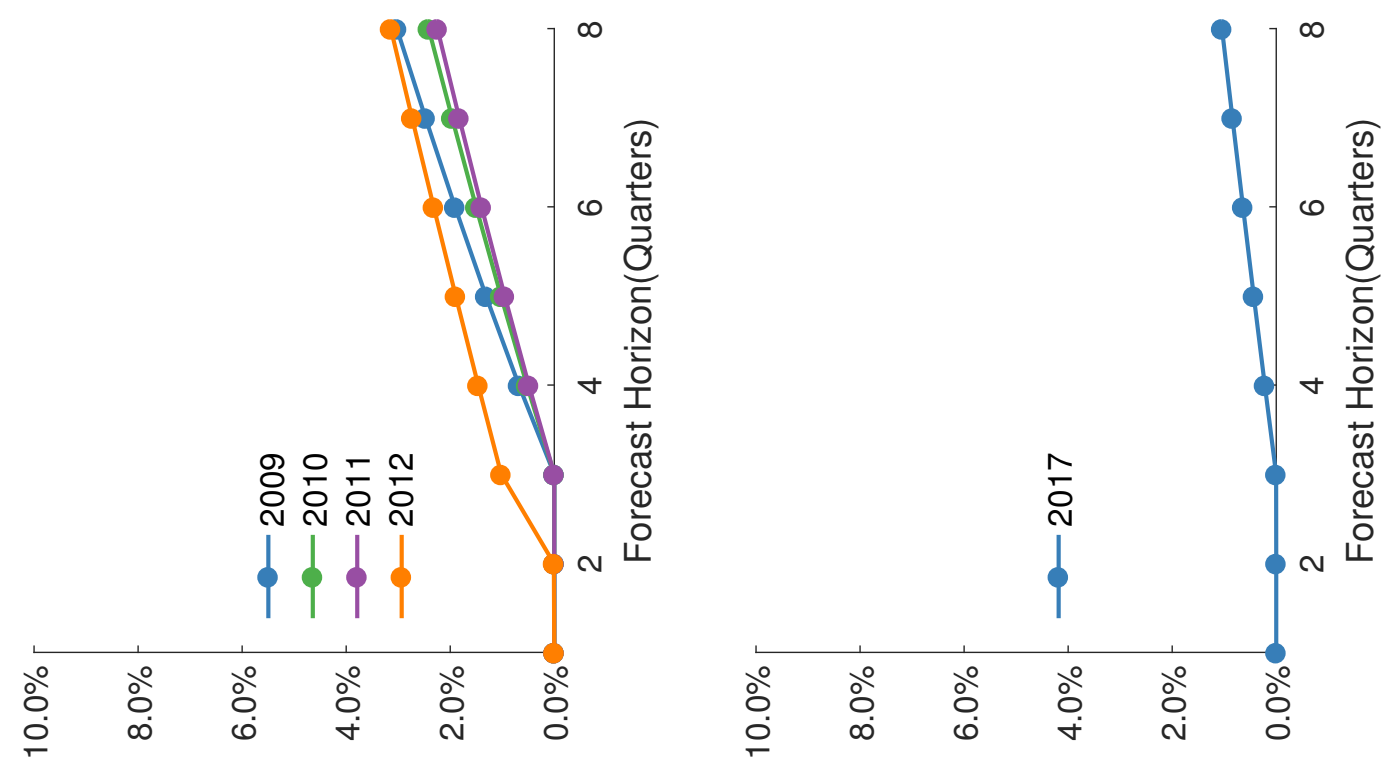

它
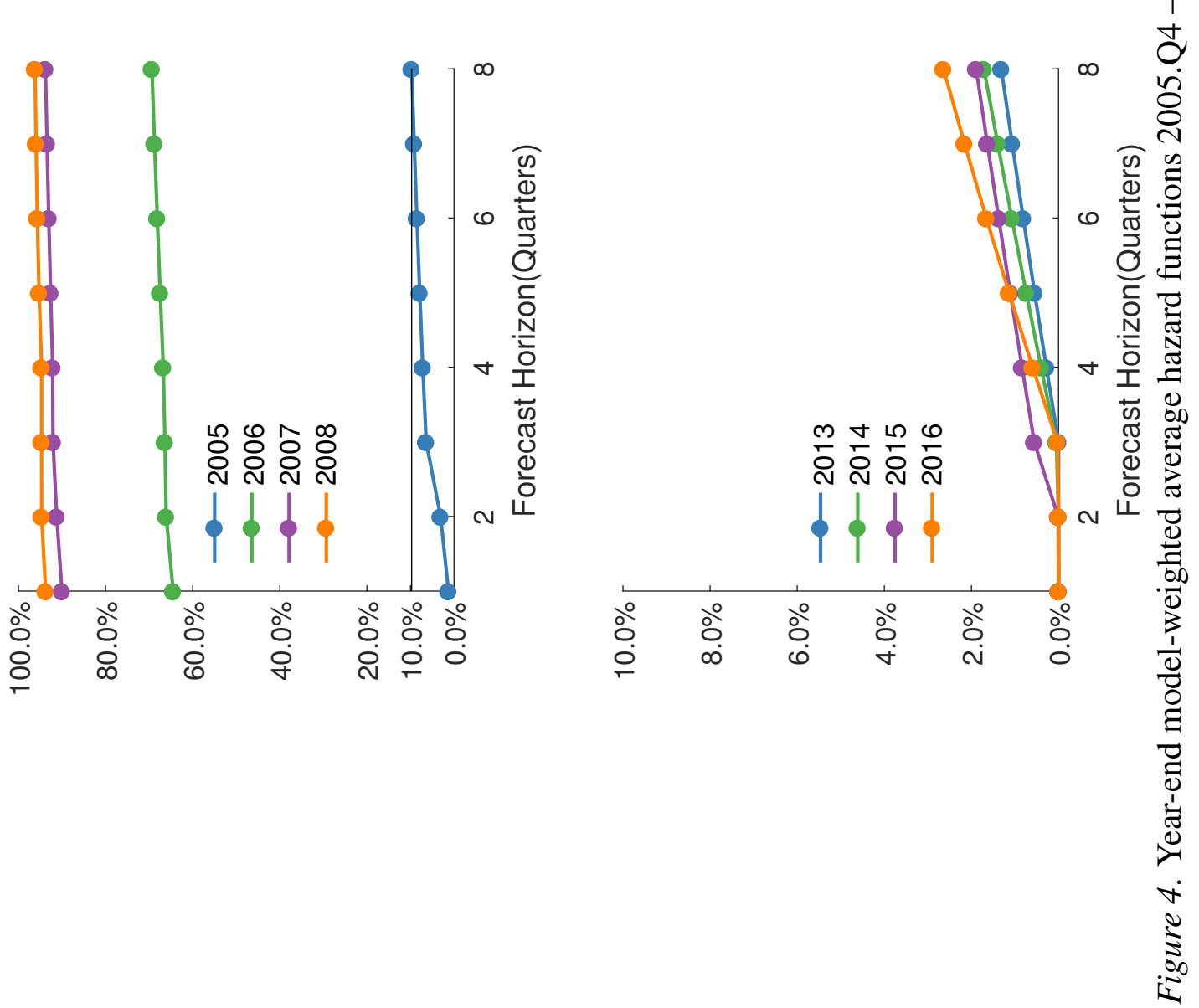


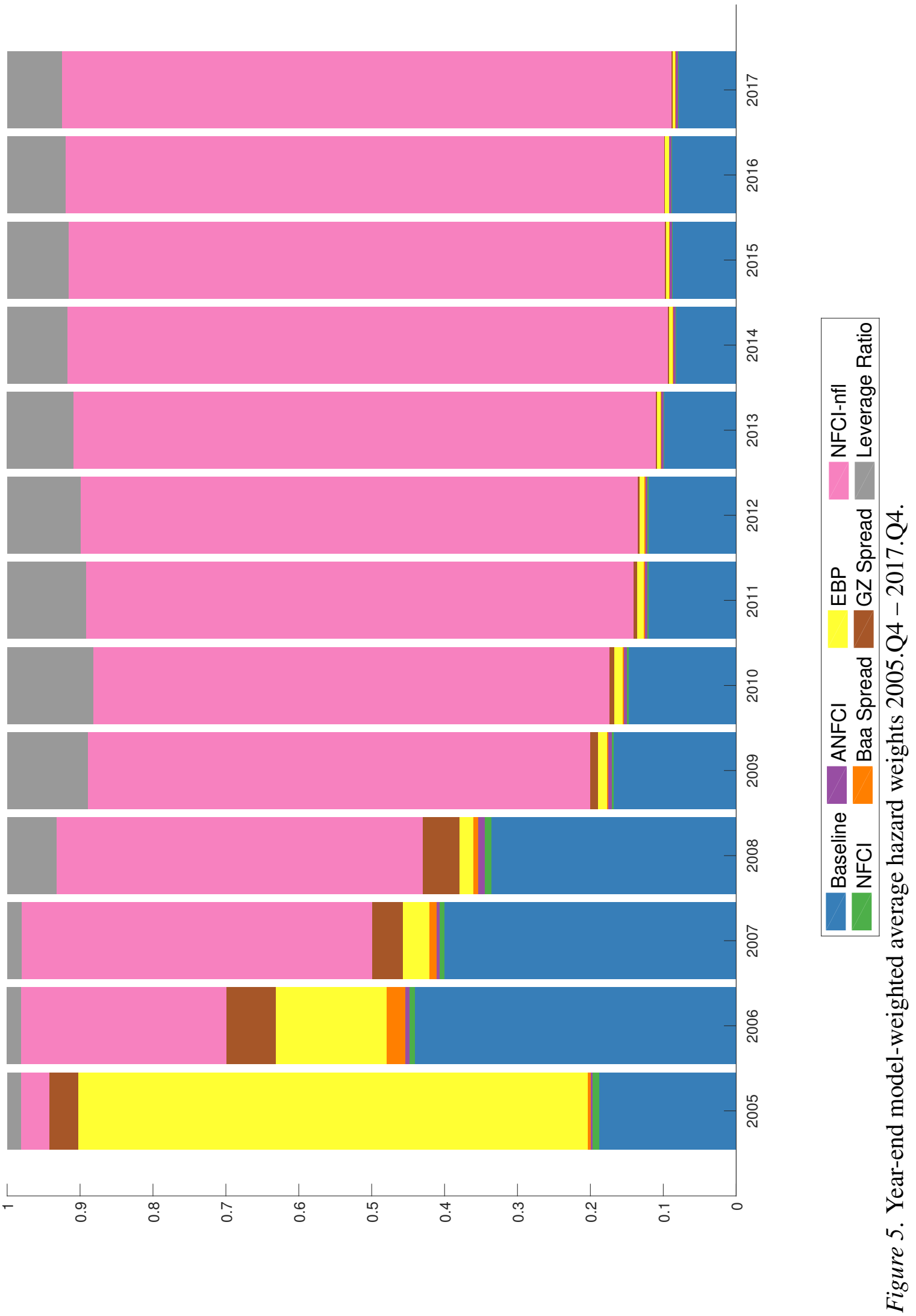




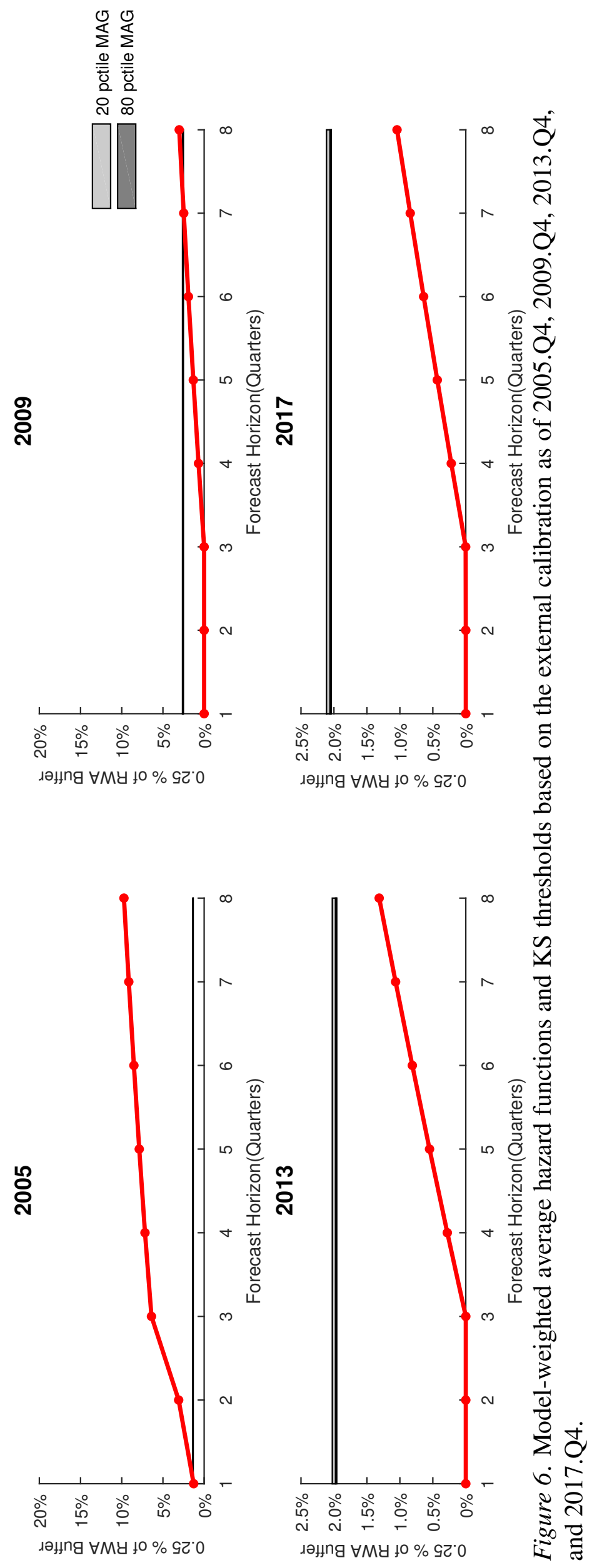



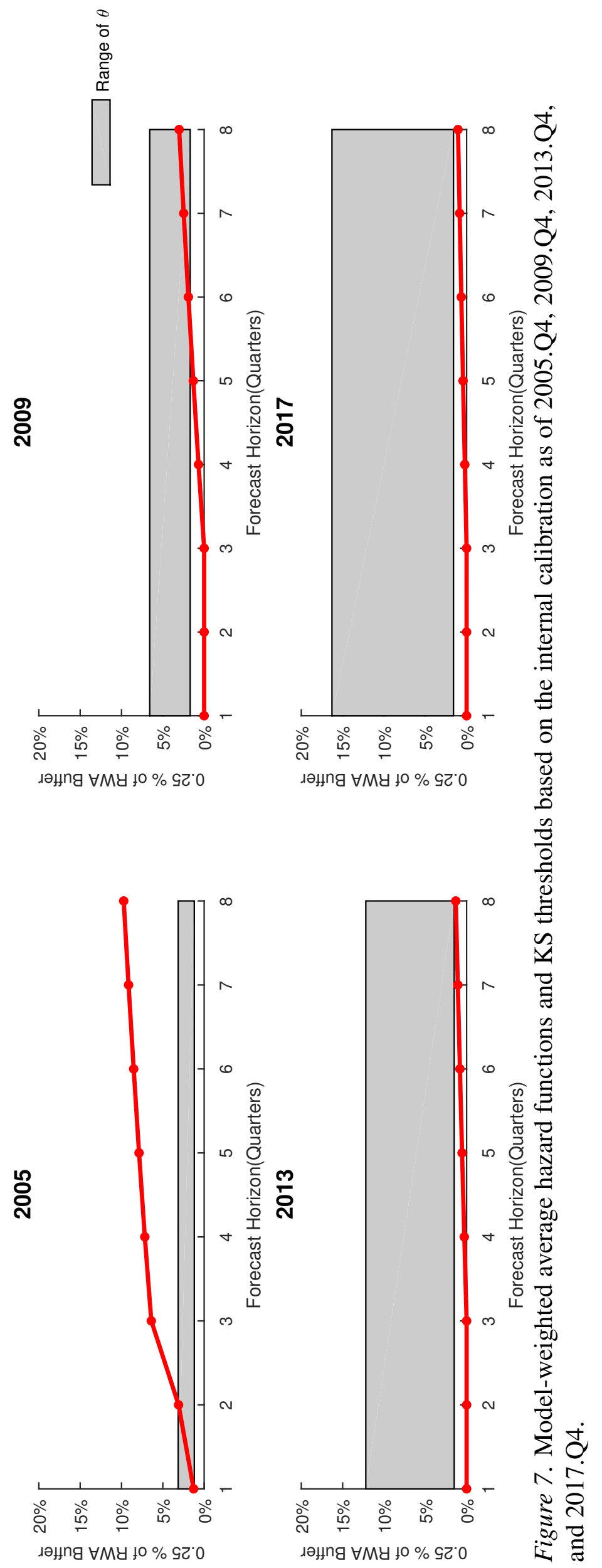

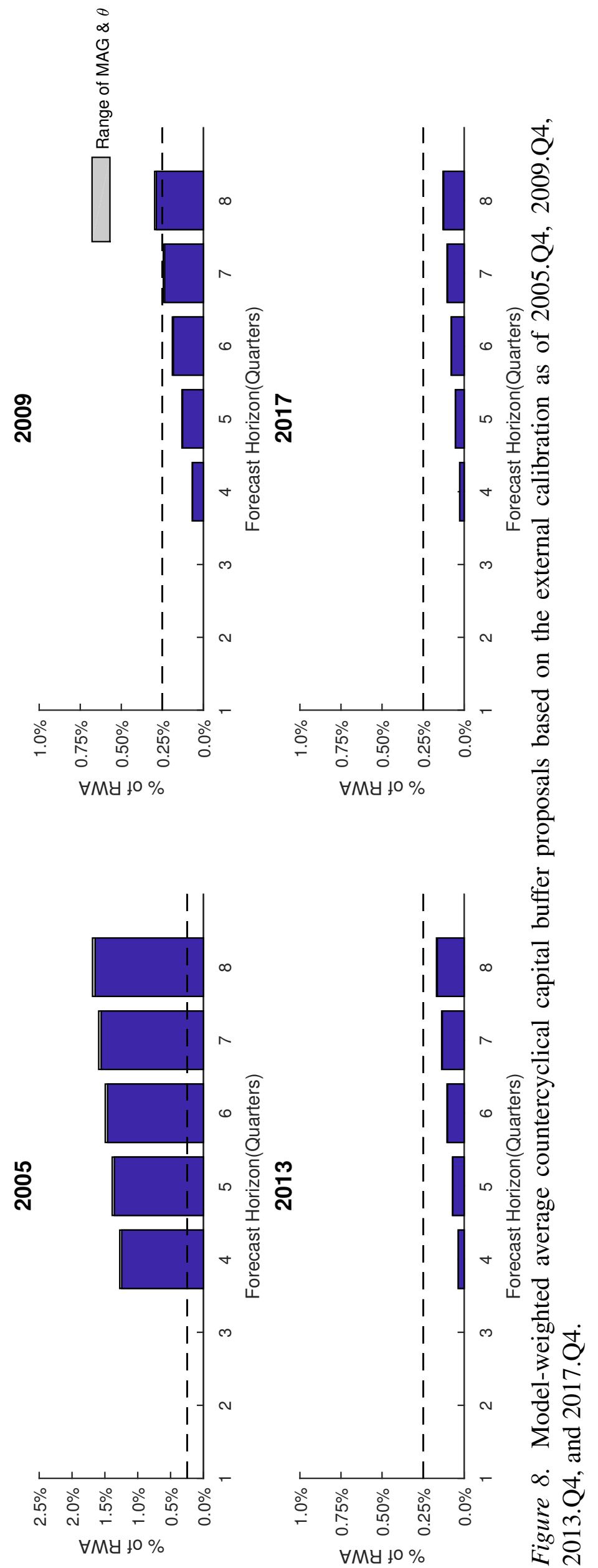

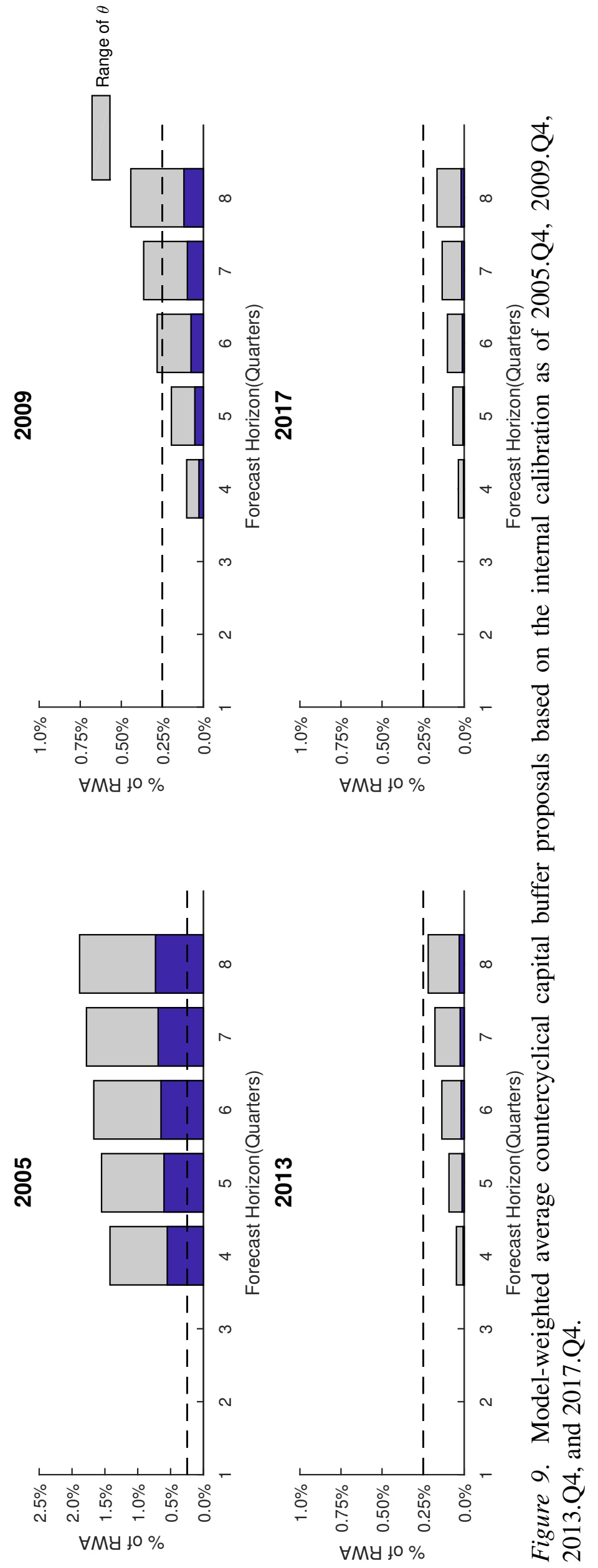


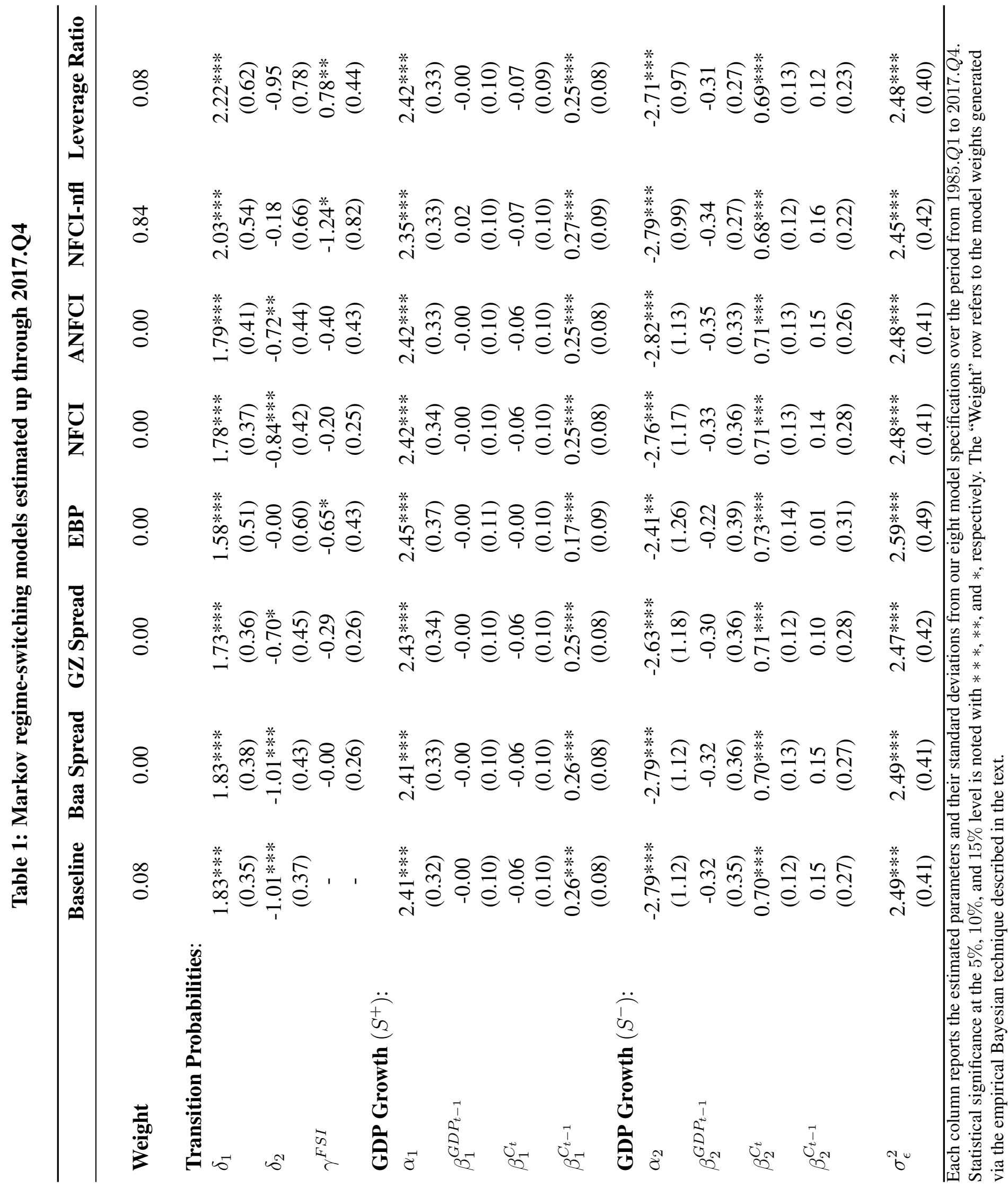


Table 2: External Calibration Parameters for KS Policy Projections 2005.Q4 2009.Q4 2013.Q4 2017.Q4

KS Parameters:

$\begin{array}{lcccc}\text { RWA for top 12 BHCs (\$b) } & \$ 4,807 & \$ 6,829 & \$ 6,348 & \$ 6,750 \\ \text { CCyB ratio } & 0.25 \% & 0.25 \% & 0.25 \% & 0.25 \% \\ \text { CCyB cost }(\$ b) & \$ 12.0 & \$ 17.1 & \$ 15.9 & \$ 16.9 \\ \text { 2-year Treasury rate } & 4.41 \% & 1.14 \% & 0.38 \% & 1.89 \% \\ \text { GDP at year-end } & \$ 14,373 & \$ 14,542 & \$ 15,794 & \$ 17,287 \\ & & & & \\ \text { SPF real GDP growth rate } & 3.40 \% & 2.40 \% & 2.60 \% & 2.50 \% \\ \bar{u}(\$ b) & \$ 994 & \$ 706 & \$ 832 & \$ 875 \\ \mu_{20 p c t} & 3.32 \% & 2.32 \% & 2.52 \% & 2.42 \% \\ \underline{u}_{20 p c t}(\$ b) & \$ 970 & \$ 682 & \$ 806 & \$ 846 \\ \mu_{80 p c t} & 3.38 \% & 2.38 \% & 2.58 \% & 2.48 \% \\ \underline{u}_{80 p c t}(\$ b) & \$ 988 & \$ 700 & \$ 825 & \$ 867\end{array}$

KS Values:

$\begin{array}{lllll}\theta=0.00 & 1.37 \% & 2.63 \% & 2.02 \% & 2.11 \% \\ \theta=0.25 & 1.36 \% & 2.60 \% & 2.01 \% & 2.09 \% \\ \theta=0.50 & 1.35 \% & 2.58 \% & 1.99 \% & 2.08 \% \\ \theta=0.75 & 1.34 \% & 2.56 \% & 1.98 \% & 2.06 \% \\ \theta=1.00 & & & & \\ & 1.33 \% & 2.53 \% & 1.96 \% & 2.04 \%\end{array}$

Notes: Dollar values expressed in 2009 dollars using the U.S. GDP deflator. Growth rates used to calculate $\bar{u}$ and $\underline{u}$ presented as annual percent rates, as is the SPF real GDP growth rate. 
Table 3: KS Implementation Dates by Model Specification (External)

\begin{tabular}{|c|c|c|c|c|}
\hline & \multicolumn{4}{|c|}{ Implementation Quarter } \\
\hline & 2005.Q4 & 2009.Q4 & 2013.Q4 & 2017.Q4 \\
\hline Weighted Average & 2 & 8 & - & - \\
\hline Baseline & 2 & 4 & 4 & 5 \\
\hline Baa Spread & 4 & 4 & 5 & 6 \\
\hline GZ Spread & 2 & 5 & - & 7 \\
\hline EBP & 2 & 4 & 4 & 5 \\
\hline NFCI & - & 6 & 5 & - \\
\hline ANFCI & 3 & 4 & 4 & 6 \\
\hline NFCI-nfl & 1 & - & - & - \\
\hline Leverage Ratio & 7 & - & - & 7 \\
\hline
\end{tabular}

Notes: Entries in the table correspond with the first quarter over the forecast horizon PQ1-PQ8 that the upper KS thresholds are exceeded. 
Table 4: Internal Calibration Parameters for KS Policy Projections 2005.Q4 2009.Q4 2013.Q4 2017.Q4

KS Parameters:

$\begin{array}{lcccc}\text { RWA for top 12 BHCs }(\$ b) & \$ 4,807 & \$ 6,829 & \$ 6,348 & \$ 6,750 \\ \text { CCyB ratio } & 0.25 \% & 0.25 \% & 0.25 \% & 0.25 \% \\ \text { CCyB cost }(\$ b) & \$ 12.0 & \$ 17.1 & \$ 15.9 & \$ 16.9 \\ \text { 2-year Treasury rate } & 4.41 \% & 1.14 \% & 0.38 \% & 1.89 \% \\ \text { GDP at year-end } & \$ 14,373 & \$ 14,542 & \$ 15,794 & \$ 17,287 \\ & & & & \\ \bar{u}(\$ b) & \$ 1,110 & \$ 1,051 & \$ 1,080 & \$ 1,121 \\ \quad \mu_{+} & 3.79 \% & 3.55 \% & 3.36 \% & 3.19 \% \\ \underline{u}(\$ b) & \$ 430 & \$ 282 & \$ 147 & \$ 125 \\ \quad \mu_{-} & 1.48 \% & 0.97 \% & 0.46 \% & 0.36 \%\end{array}$

KS Values:

\begin{tabular}{lllll}
$\theta=0.00$ & $3.14 \%$ & $6.58 \%$ & $12.20 \%$ & $16.29 \%$ \\
$\theta=0.25$ & $2.23 \%$ & $3.82 \%$ & $4.39 \%$ & $4.91 \%$ \\
$\theta=0.50$ & $1.73 \%$ & $2.69 \%$ & $2.68 \%$ & $2.89 \%$ \\
$\theta=0.75$ & $1.41 \%$ & $2.07 \%$ & $1.93 \%$ & $2.05 \%$ \\
$\theta=1.00$ & $1.19 \%$ & $1.69 \%$ & $1.50 \%$ & $1.59 \%$ \\
\hline
\end{tabular}

Notes: Dollar values expressed in 2009 dollars using the U.S. GDP deflator. Growth rates used to calculate $\bar{u}$ and $\underline{u}$ presented as annual percent rates. 
Table 5: KS Implementation Dates by Model Specification (Internal)

\begin{tabular}{|c|c|c|c|c|}
\hline & \multicolumn{4}{|c|}{ Implementation Quarter } \\
\hline & 2005.Q4 & 2009.Q4 & 2013.Q4 & 2017.Q4 \\
\hline Weighted Average & 1 & 6 & - & - \\
\hline Baseline & 2 & 4 & 4 & 4 \\
\hline Baa Spread & 3 & 4 & 5 & 5 \\
\hline GZ Spread & 2 & 4 & 8 & 6 \\
\hline EBP & 2 & 4 & 4 & 4 \\
\hline NFCI & - & 5 & 4 & - \\
\hline ANFCI & 2 & 4 & 4 & 5 \\
\hline NFCI-nfl & 1 & - & - & - \\
\hline Leverage Ratio & 6 & - & - & 7 \\
\hline
\end{tabular}

Notes: Entries in the table correspond with the first quarter over the forecast horizon PQ1-PQ8 that the lower KS thresholds are exceeded. 


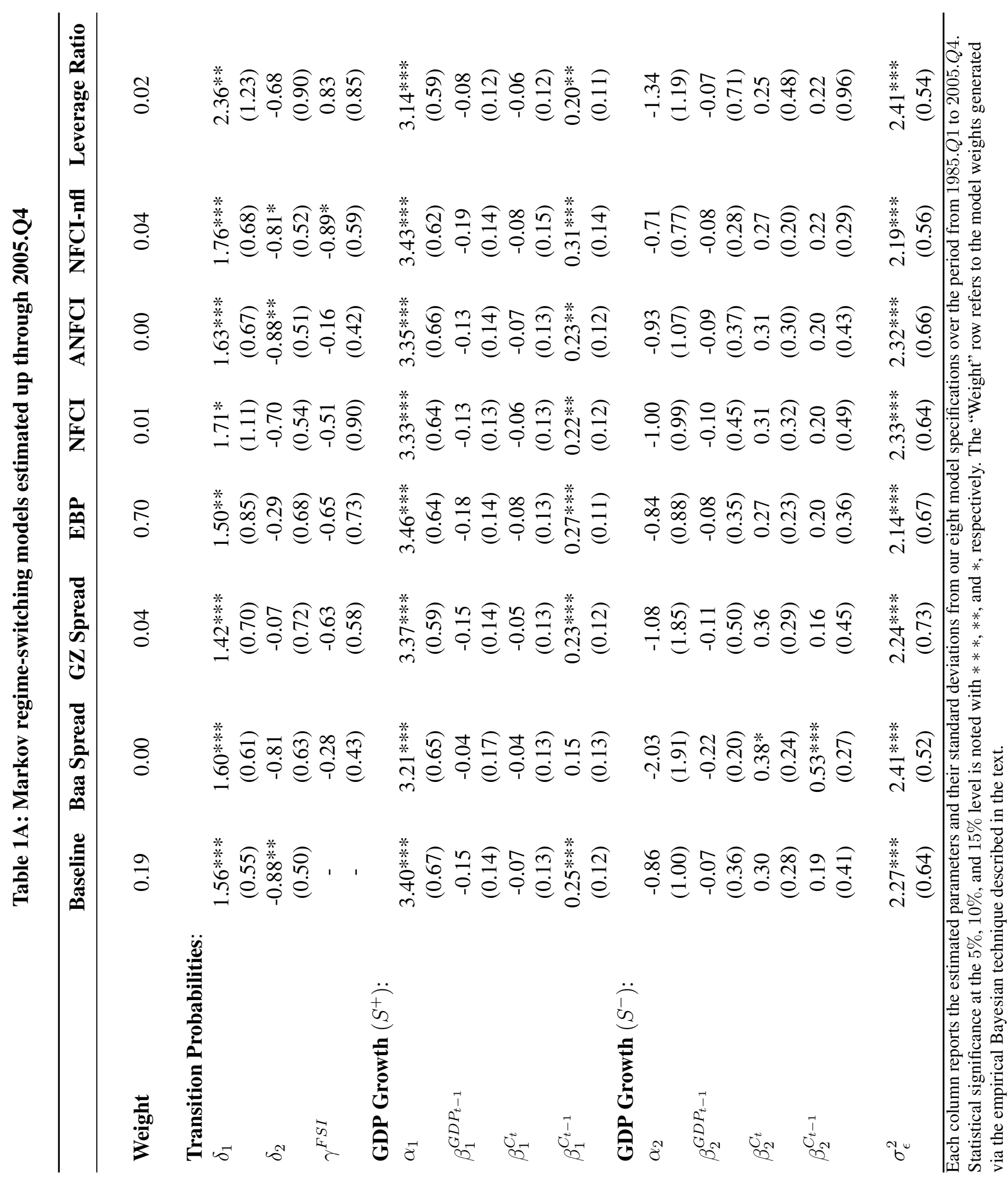




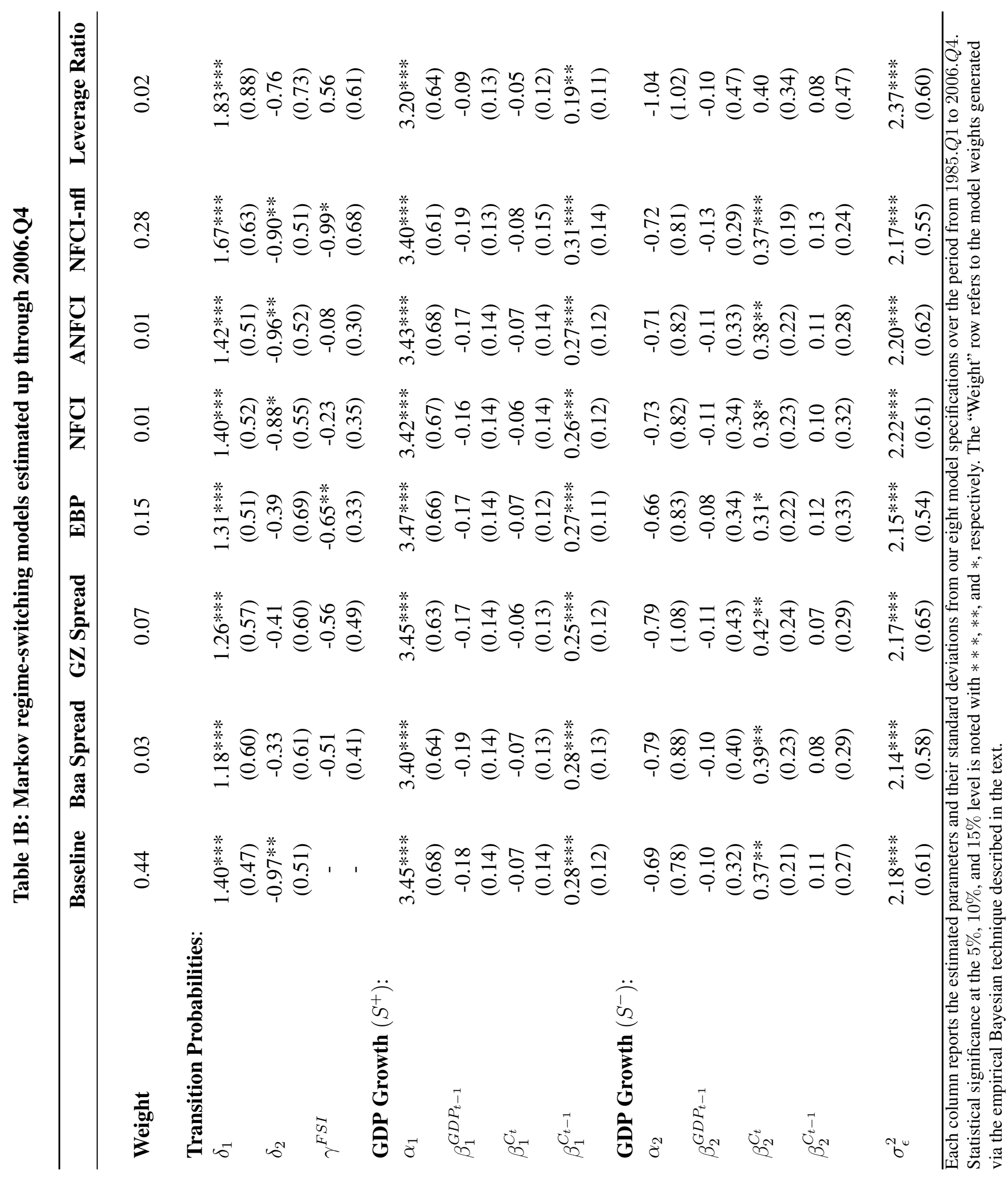




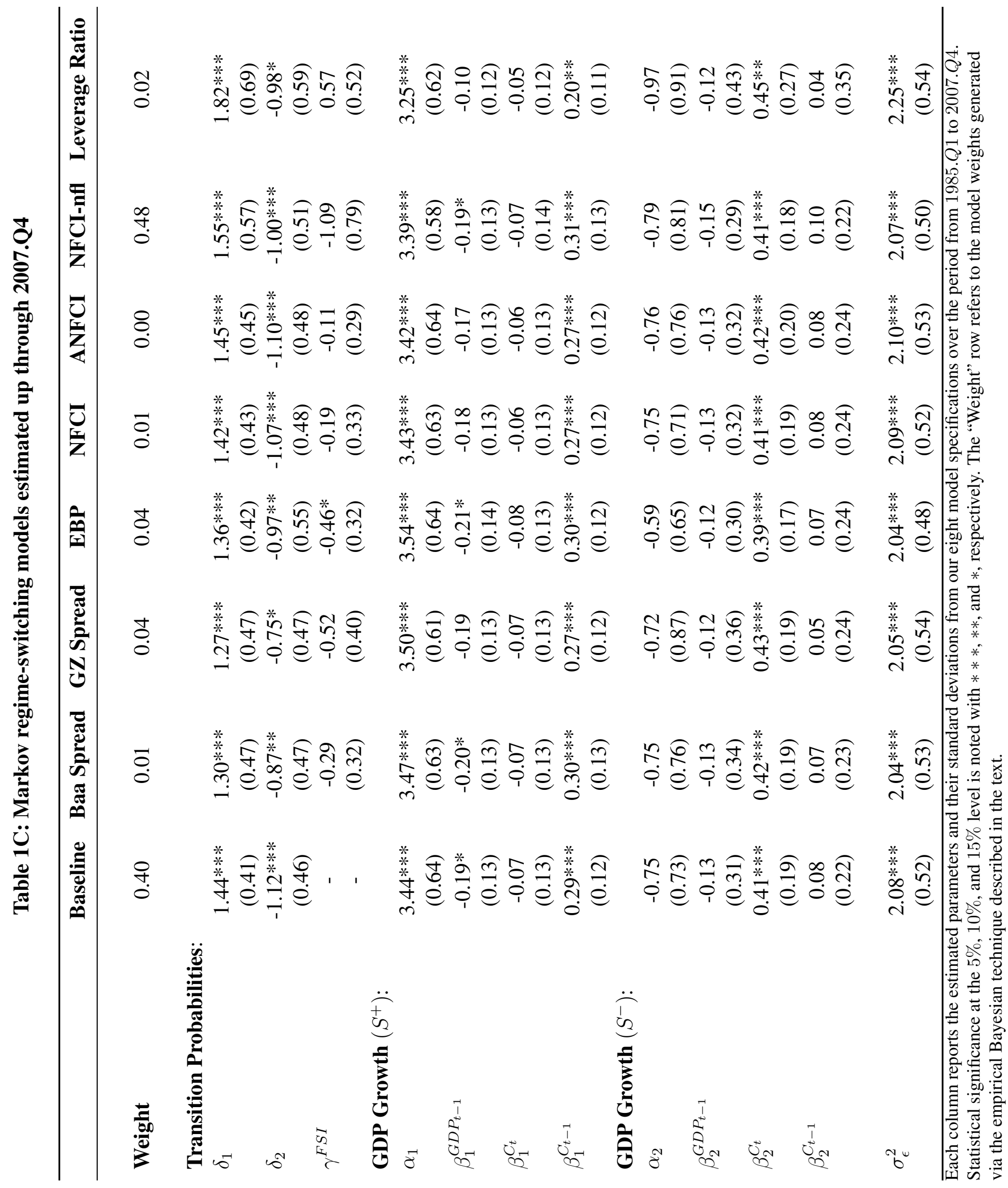




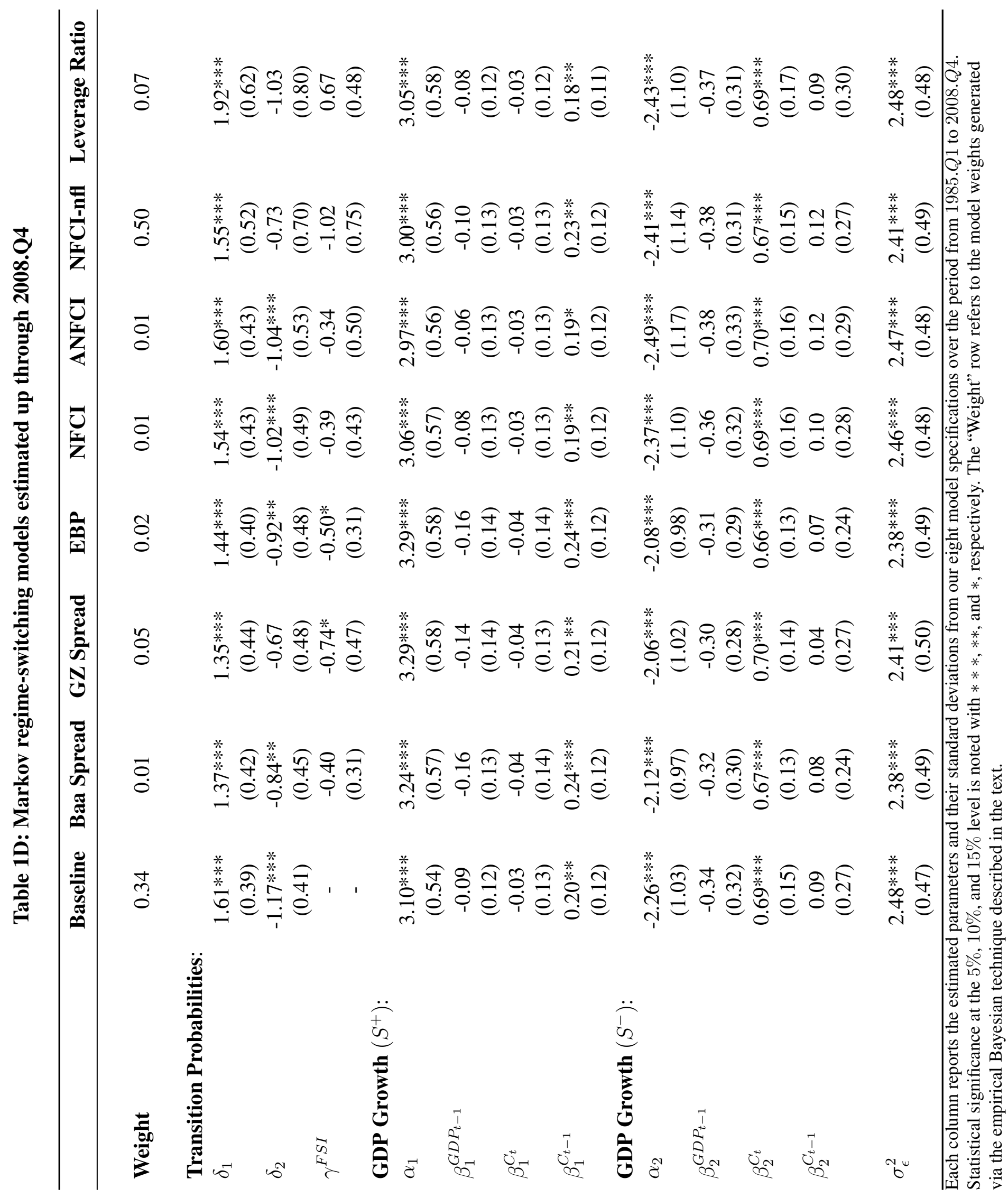




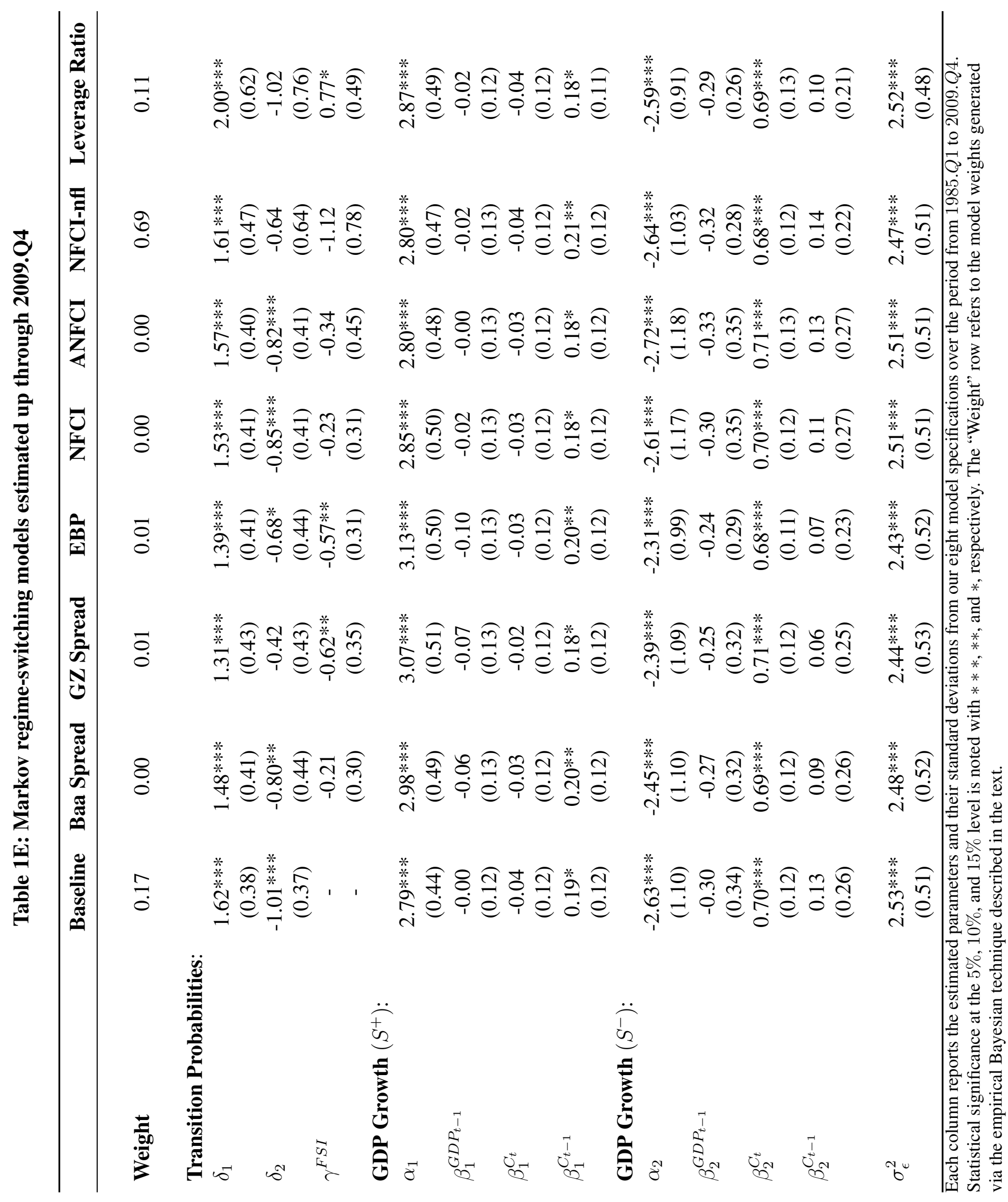




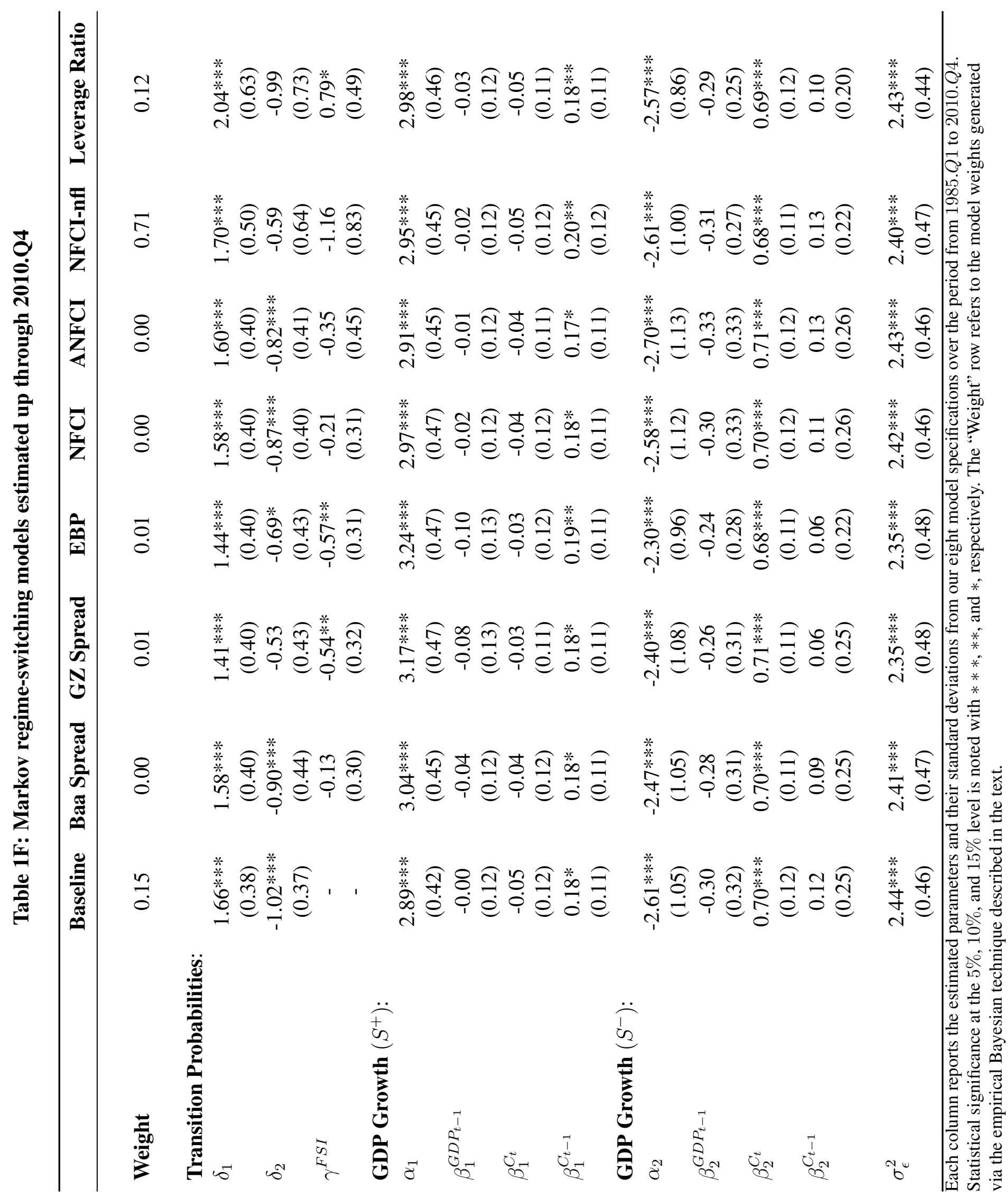




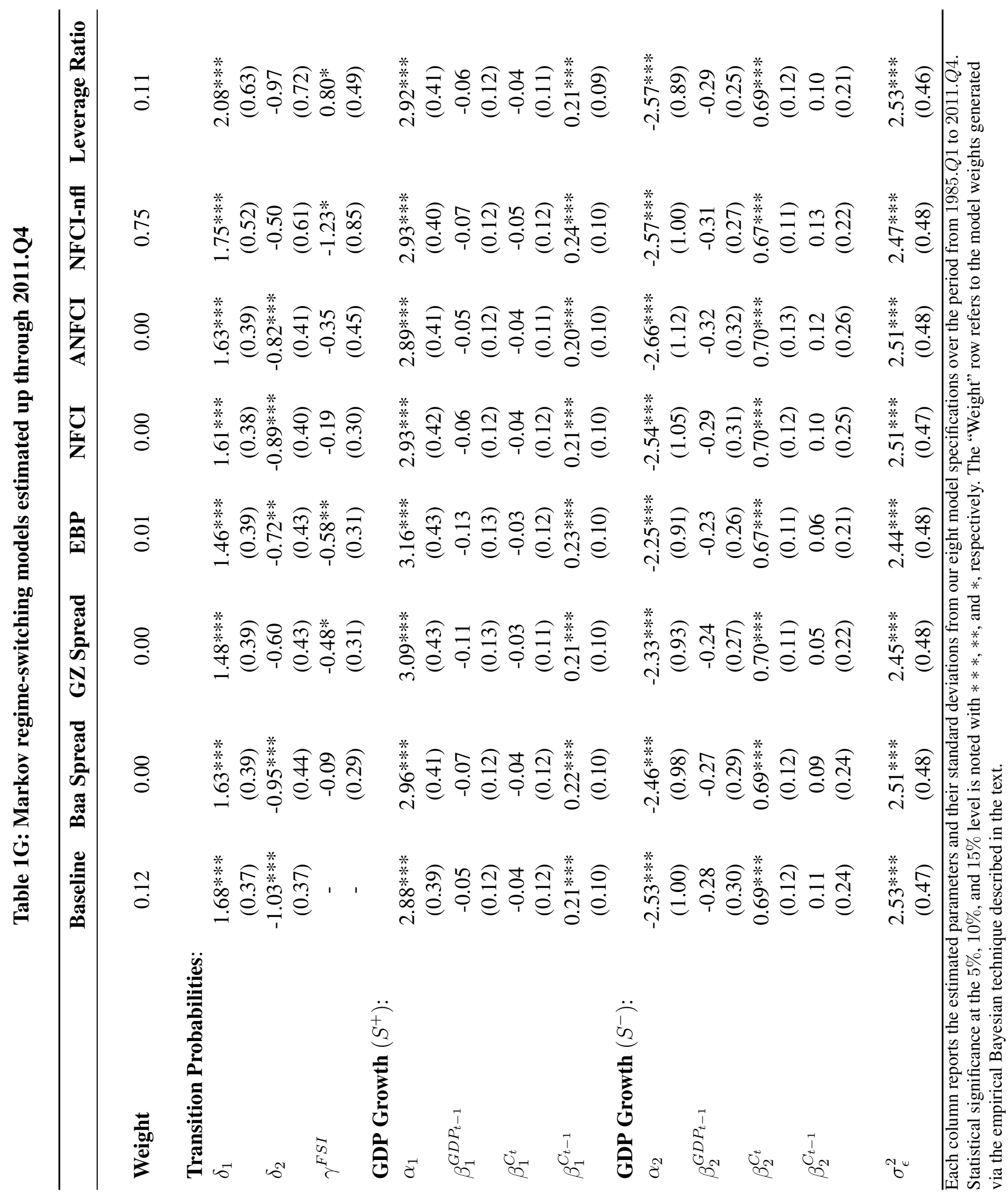




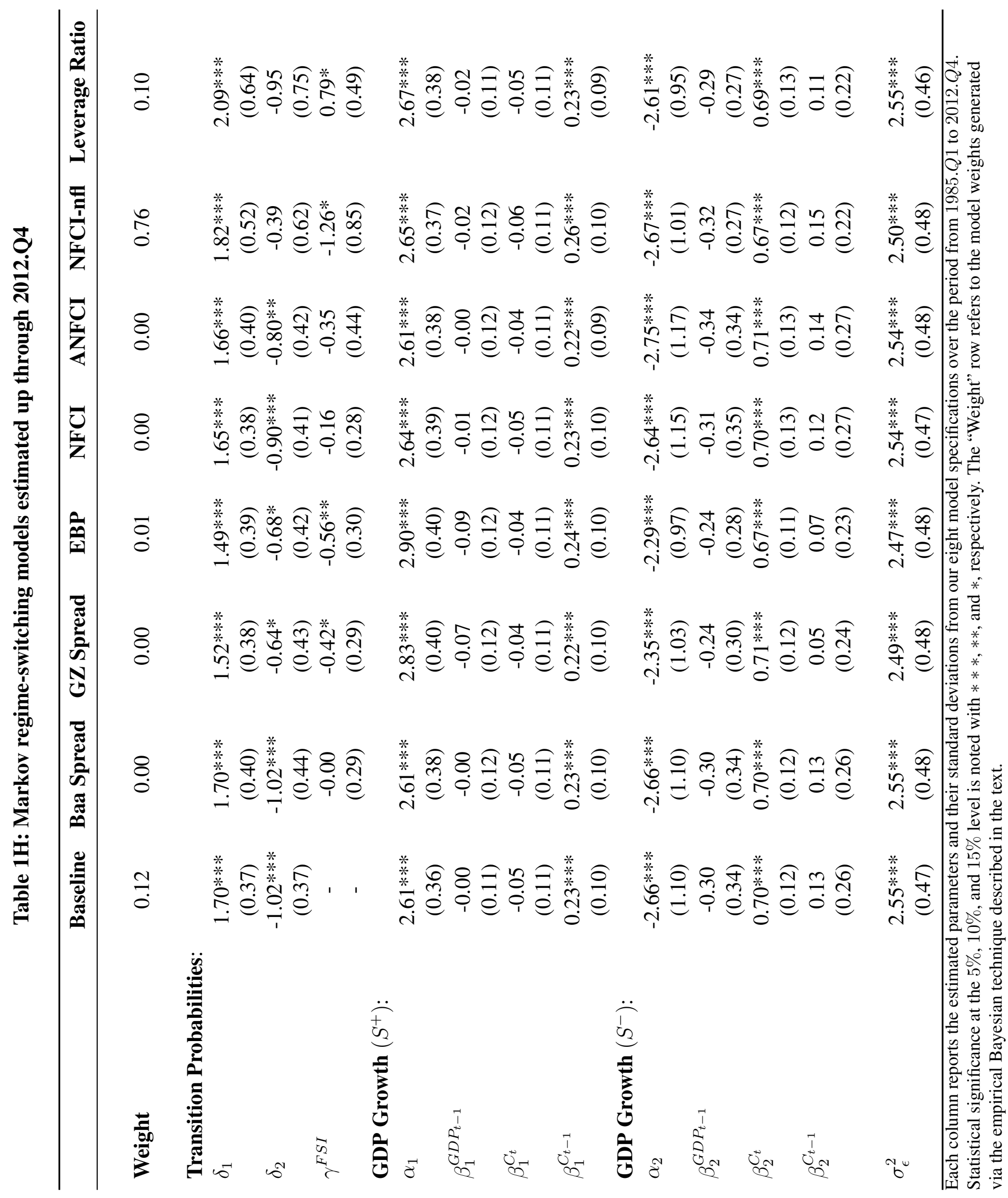




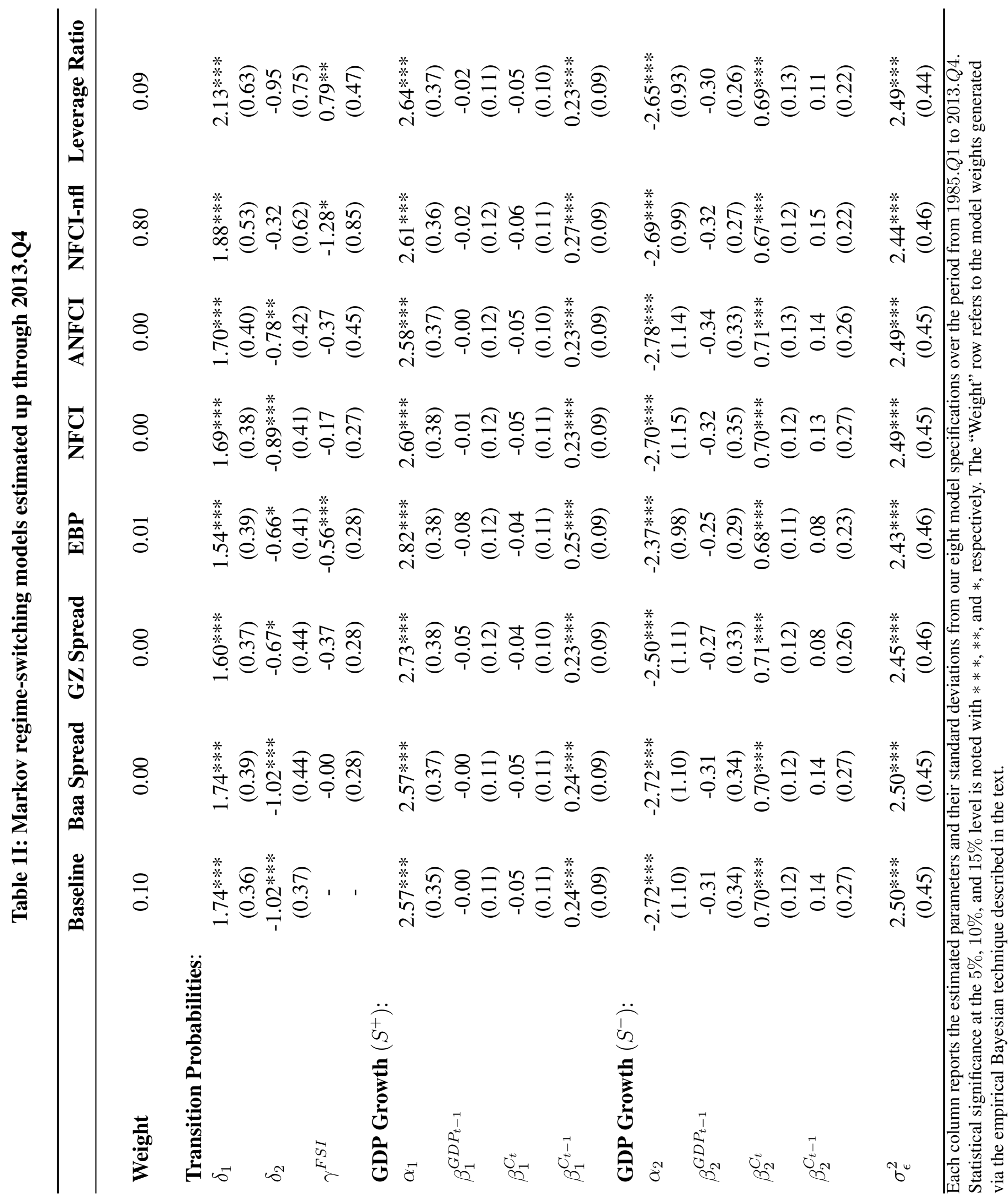




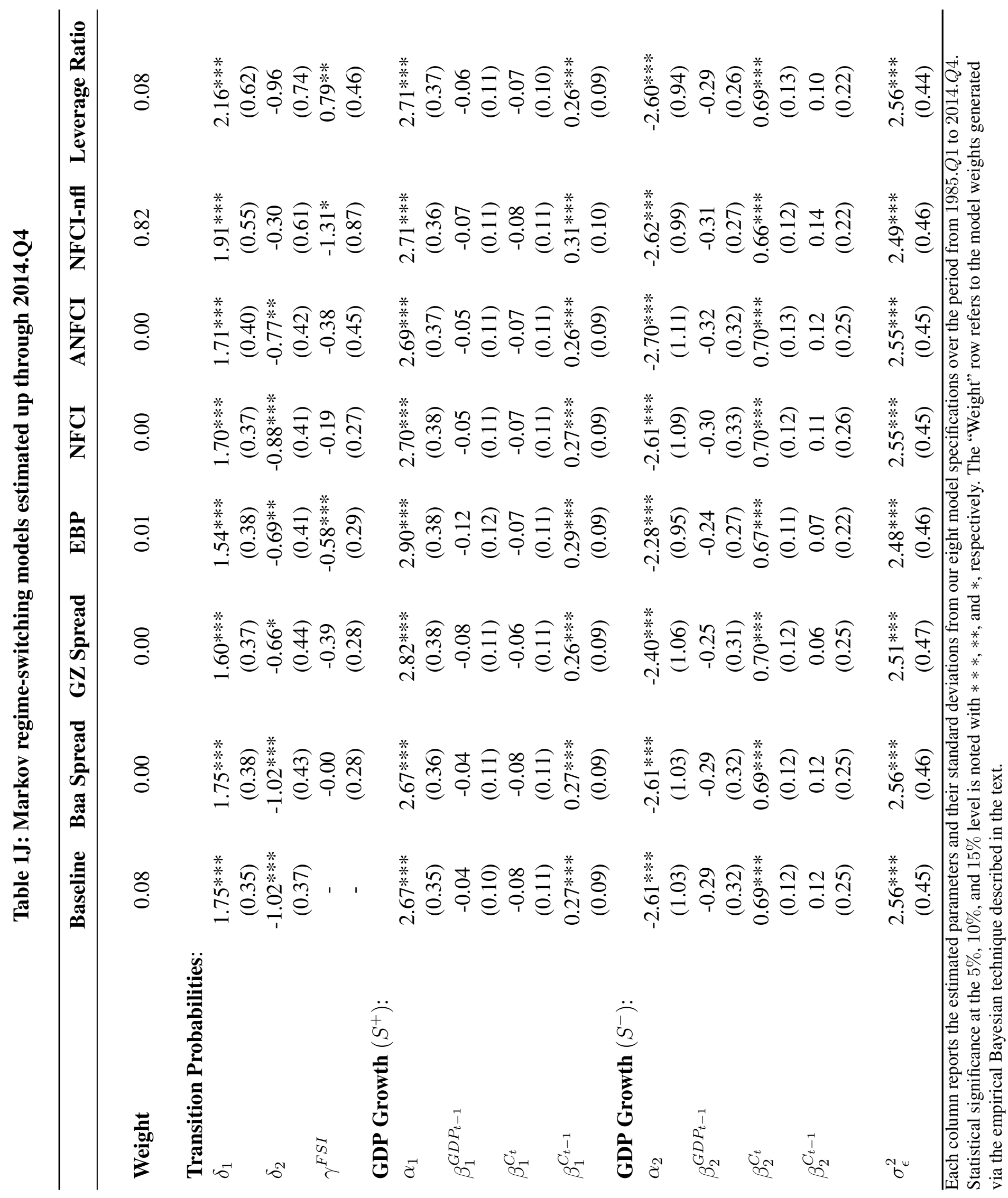




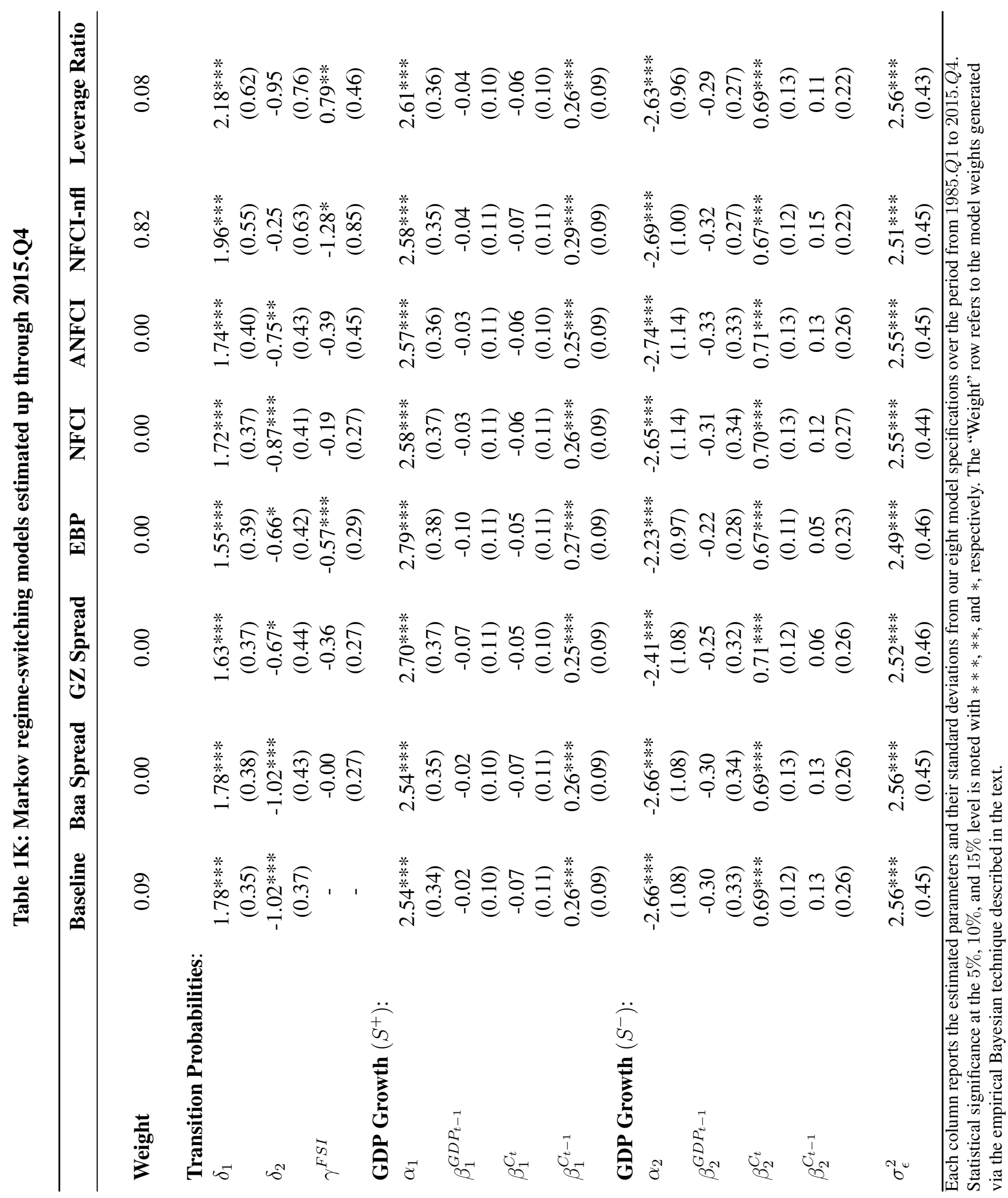




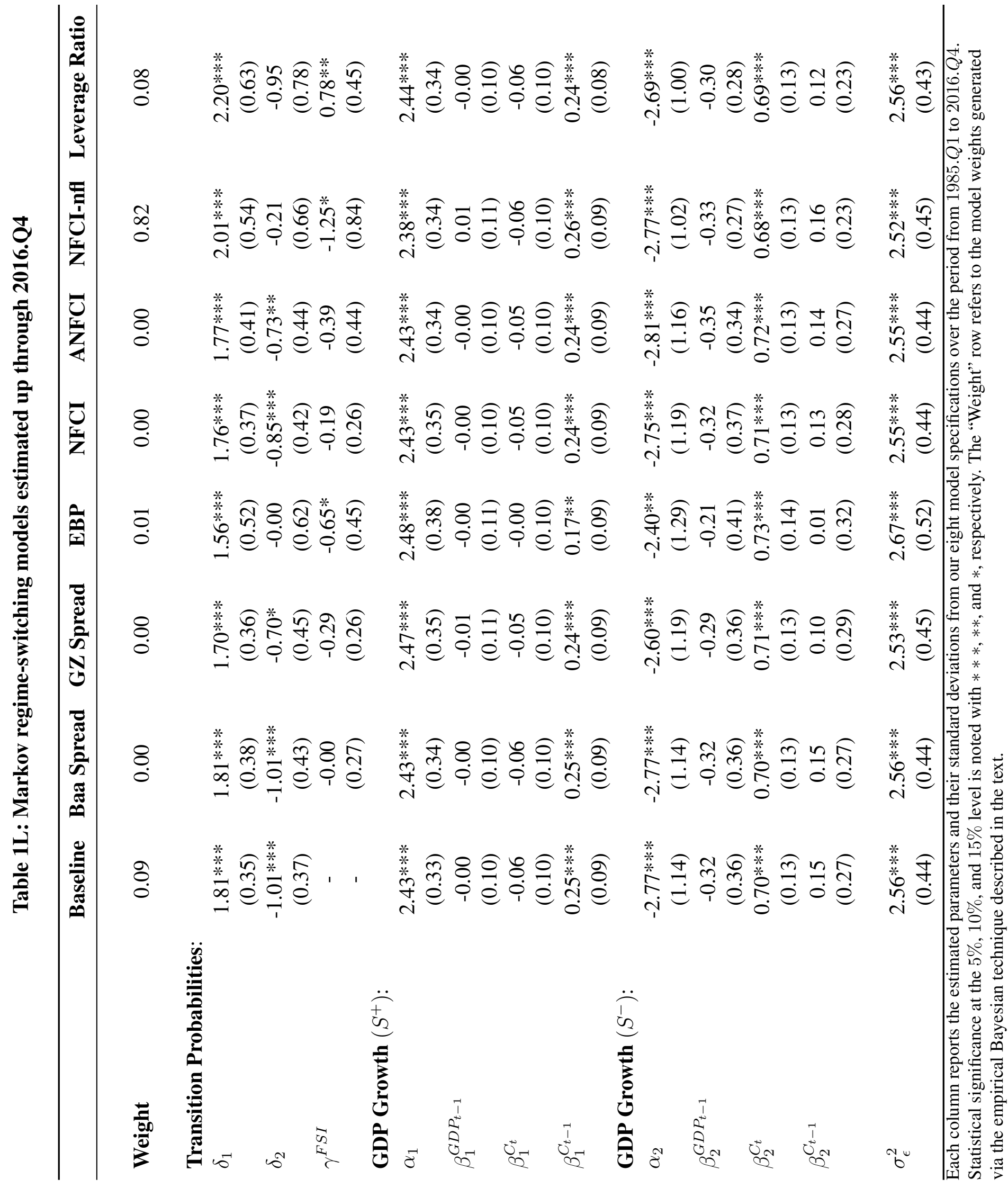

